\title{
Confronting Farmers' Perceptions of Climatic Vulnerability with Observed Relationships between Yields and Climate Variability in Central Argentina
}

\author{
VALERIA HERNANDEZ \\ UMR 245 Centre d'études en sciences sociales sur les mondes africains, américains et asiatiques, \\ Université Paris Diderot/Institut de Recherche pour le Développement, Paris, France \\ VINCENT MORON \\ Aix-Marseille Université and CEREGE, UM 34 CNRS, Aix en Provence, France, and International \\ Research Institute for Climate and Society, Columbia University, Palisades, New York \\ FLORENCIA FOSSA RigLOS \\ Universidad Nacional de San Martín, Buenos Aires, Argentina \\ EUGENIA MuZI \\ Instituto Nacional de Tecnología Agropecuaria, Buenos Aires, Argentina
}

(Manuscript received 16 September 2013, in final form 31 July 2014)

\begin{abstract}
Farmers' perceptions of climate variability is compared with the sensitivity of observed yields for wheat, maize, soybean, and sunflower crops to interannual and intra-annual climate variability in two districts (Junín and San Justo) in central Argentina from the 1970s. A recent transition occurred here between mixed crop and livestock farming to a more specialized system, dominated by transgenic soybean combined with glyphosate. According to the ethnographic fieldwork, farmers ranked drought first and flood second as the main adverse climate factors in both districts. Overall, the farmers' representations fit rather well with the observed relationships between interannual variability of yields and rainfall, especially in Junín. The adverse impact of long-lasting dry spells, especially during the first half of the crop cycle, is usually combined with the more linear impact of large rainfall amounts (anomalously positive/negative rainfall amounts associated with anomalously positive/negative yields) during the second half of the crop cycle. This relationship is strong for soybeans, similarly large for maize, far weaker for wheat, and reversed for sunflower, which is the only crop that benefits, on average, from anomalously low rainfall amounts at a specific stage of the crop cycle. The adverse effect of flood on soybeans and maize seems less phase-locked and more diluted across the crop cycle. This paper presents the argument that climate and society have a complex relationship, requiring an integrated analysis of the social context, people's perceptions of climate, and scientific climate knowledge. The concept of "climate social significance" is proposed in order to highlight the strategies implemented by different socioproductive groups to address adverse climate events.
\end{abstract}

\section{Introduction}

The relationship between climate and how it is understood by local communities is characterized as "perception," lending this subject to subjectivity analysis

Corresponding author address: Maria Florencia Fossa Riglos, Av. 25 de Mayo y Martín de Irigoyen, 2nd floor, Office 15, San Martín, Buenos Aires, ZC: 1650, Argentina.

E-mail: florenciafr@gmail.com
(Leiserowitz 2005, 2007; Schlindwein et al. 2011; Bonatti 2011; Boulanger 2012; Aberra 2012). The studies usually begin with a questionnaire to evaluate the climatic effects on various socioeconomic sectors. For example, farmers are asked to identify the climatic characteristics they use to establish their agricultural calendar. These surveys are then compared with climate variability so that climate experts can assess the accuracy of the perceptions. Therefore, surveys are important for analyzing 
the most important climatic factors affecting perceived vulnerability, such as the major impact of drought on most famines in Kenya (Speranza et al. 2008). In a similar climatic context, Tanzanian farmers ranked drought as their major productivity-reducing problem, but they also scaled drought vulnerability according to different soils and land uses (Slegers 2008). In Senegal, Mertz et al. (2009) found that farmers did not assign climate factors as the main reason for livelihood change. Nevertheless, they identified strong winds and occasional excessive rainfall as the most destructive climate factors. Similarly, in central-south Senegal, Tschakert (2007) showed that climate also did not directly appear in people's risk assessments. In contrast, Thomas et al. (2007) demonstrated that trends and variations in precipitation parameters, including intraseasonal characteristics related to rainfall occurrence and intensity, were clearly recognized by South African farmers living in affected areas. Perception of climate is highly dynamic in space, but also in time - an extreme year can remain prominent in people's memories in the years following.

Recently, Meze-Hausken $(2004,2007,2008)$ and SanchezCortés and Lazos Chavero (2011) emphasized the need to consider the relationships between people and climate variability in the framework of a contextual analysis that reevaluates the notion of perception as a result of the interaction between people's expectations, the evolution of societies, and the constructed nature of climatic data. Through the case of Ethiopian drought in 2002, Meze-Hausken (2004) showed how the apparent mismatch between a farmer's perception of reduced rainfall (negative anomalies) and the observed amount (close to normal rainfall) can be reconciled only if we take into account the historical and social dimensions of the dynamic cropping system, including the local-scale increase of the agricultural production due to intensive farming. As a consequence, the amount of rainfall considered as "enough" increased and a close-to-normal year, climatologically speaking, may be perceived as a drought year. Individual expectations must be related to societal evolution: in the Ethiopian case, demographic growth and related increase of food demand should be taken into account to understand the increase of the "normal" level. This study more generally questioned the construction of scientific data used to define a reference level and relative anomalies. For example, "normality" is a multifaceted state combining many variables from the economical, social, political, and geographical dimensions rather than a specific statistical moment. Additionally, Meze-Hausken (2007) introduced the notion of multidimensionality to account for this comprehensive perception. With the same objective of preserving the complexity of the phenomena under analysis, Agar (2004) highlighted the superiority of ethnographic fieldwork (i.e., questionnaires, focus groups, workshops, and thematic seminars) to other methodological procedures. In fact, the results from ethnographic work are reinforced by the social interactions that are analyzed in a global and historical context.

Our methodological approach complements the above theoretical notions [particularly that of multidimensionality proposed by Meze Hausken (2007)] and emphasizes two supplementary aspects. First, we point out the necessity of applying microsocial studies to account for the concrete ways in which diverse social actors consider climate variables in relation to other socioeconomic factors. Second, given the interaction between scientific climate knowledge and its social contexts, we emphasize the importance of questioning knowledge transfer approaches. The ways in which climate knowledge is appropriated and engaged are not linear or individually decided; rather, they are the result of a configuration of various individual and structural factors such as macroeconomics and soil's agronomic properties (Gieryn 1999; Gibbons 1999). Thus, climatic variability is socially constructed through the notion of "climate social significance," which allows us to understand the articulation modalities among diverse factors built by social actors.

In this paper, we adopt an interdisciplinary approach with the main goal of analyzing the complexity of climatic impacts upon observed yields of four main crops (wheat, soybean, maize, and sunflower) in central Argentina, and the farmers' perceptions of the main climate-related risks in two rural districts of the La Plata basin in central Argentinean Pampas (Junín and San Justo), where agriculture is by far the most dominant sector of the local economy (Magrin et al. 2005; Caviglia and Andrade 2010). The research sites (mean climate and crop production, areas, and yields) are presented in section 2, the ethnological approach is presented in section 3, the relationship between yields and climate variability is detailed in section 4 , and a discussion and conclusions close the paper in section 5 .

\section{Research sites}

Junín $\left(34^{\circ} 35^{\prime} \mathrm{S}, 60^{\circ} 56^{\prime} \mathrm{W}\right)$, located in the northwest of Buenos Aires province $258 \mathrm{~km}$ from the Argentinean capital (Fig. 1a), covers an area of 226337 ha and has a population of 94926 inhabitants (CNPyV 2010). San Justo $\left(30^{\circ} 47^{\prime} \mathrm{S}, 60^{\circ} 35^{\prime} \mathrm{W}\right)$ is in the north-central region of Santa Fe Province, $557 \mathrm{~km}$ from the country's capital (Fig. 1a). Its district covers a surface of 557500 ha and it has a population of 40904 inhabitants (CNPyV 2010). An equivalent area is studied at each site ( 110000 ha in Junín and 116800 ha in San Justo). These districts are 
(b) San Justo

(a) General map

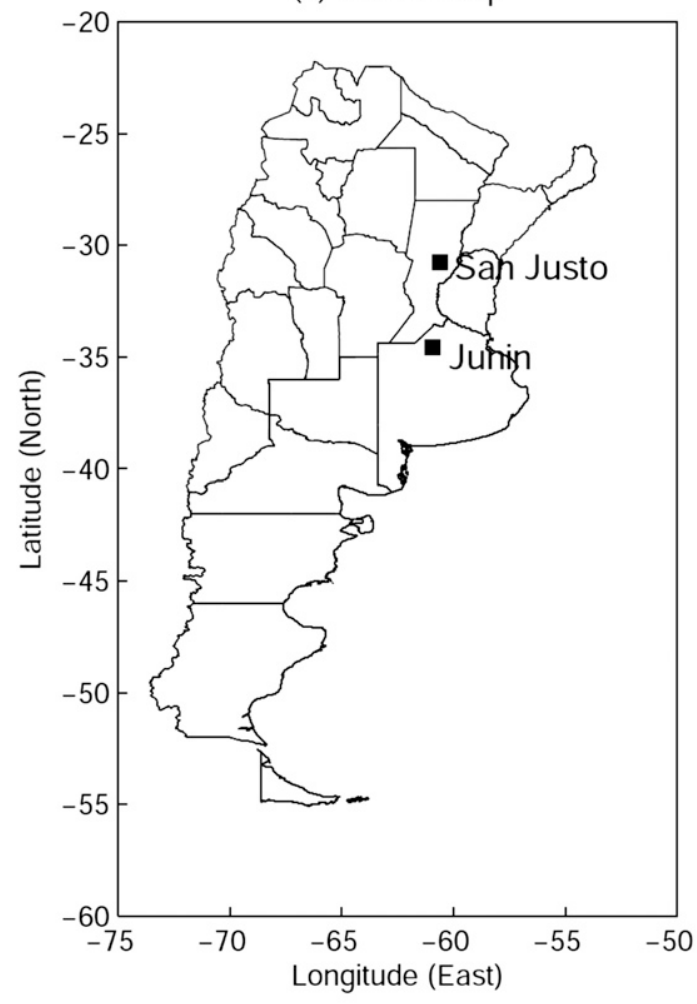

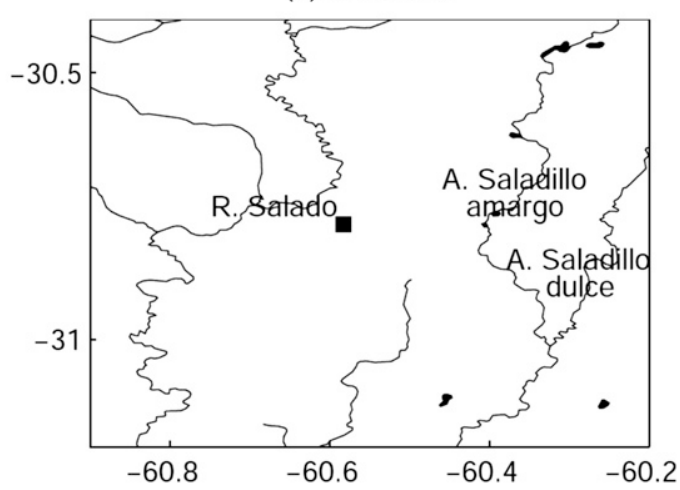

(c) Junin

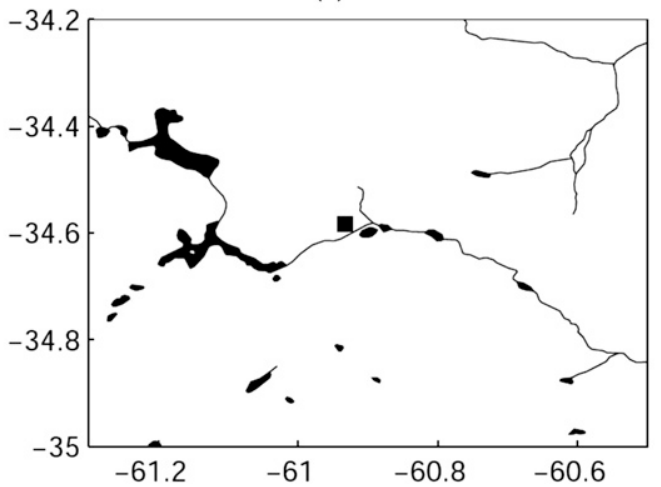

FIG. 1. Map of location of the two sites of research in Argentina.

$\sim 400 \mathrm{~km}$ far apart and share a similar temperate humidsubhumid climate with annual rainfall close to $1000 \mathrm{~mm}$, a long wet season during the warm austral summer, and a shorter, drier season during the cool winter. The annual temperature cycle is typical for subtropical latitudes with cooler conditions in Junín (by an average $2^{\circ} \mathrm{C}$ ) than in Rafaela, a town $70 \mathrm{~km}$ from San Justo (no long-term temperature records exist for this location). Frost occurs 22 days $\mathrm{yr}^{-1}$ with a minimum temperature below or equal to $0^{\circ} \mathrm{C}$ in Junín and 10 days $\mathrm{yr}^{-1}$ in Rafaela. The absolute minimum temperature is $\sim-8^{\circ} \mathrm{C}$ at both stations.

Junín soils are dominated by molisols (mineral soils rich in organic matter) covering pastures suitable for agriculture activity (Alvarez and Lavado 1998). Altogether, $80 \%$ of Junín's soil is considered best for agricultural use, and the remaining area is used for livestock production $(14 \%)$ or covered by lagoons $(6 \%)$. In San Justo, poorly drained natracualfes (saline-sodium and sodium soils) dominate the area west of the Salado River and east of the Saladillos streams (Fig. 1b), In the central sector, soils are finer and moderately well drained (argiudolls). Approximately $44 \%$ of the district is suitable for agricultural use but, within this fraction, only $29 \%$ has high production capability; the rest has middle-high (40\%) and low (31\%) suitability. Also, $38 \%$ of the land is suitable for livestock activity with low $(45 \%)$ and very low (55\%) productive capacity. The remaining $18 \%$ of the district is potential flooding areas.

The agricultural calendar (Fig. 2) is similar for both sites. Wheat, maize, and sunflower are sown in austral autumn. Wheat is harvested in the spring. Maize and sunflower are harvested close to the end of summer, from January to March. The calendar is more complicated for soybeans, which can be sown after the wheat and then harvested after the next summer/autumn. A second season can occur just after this initial harvest from autumn to the next winter (Fig. 2). Although yields vary between both harvests, Argentina's national agriculture statistics (SIIA) do not distinguish between the two types of soybeans.

Both districts are characterized, as is most of the Argentinean Pampas, by the gradual transition between mixed cropping systems (including open cattle, dairy farms, and agriculture) to a dominant transgenic 


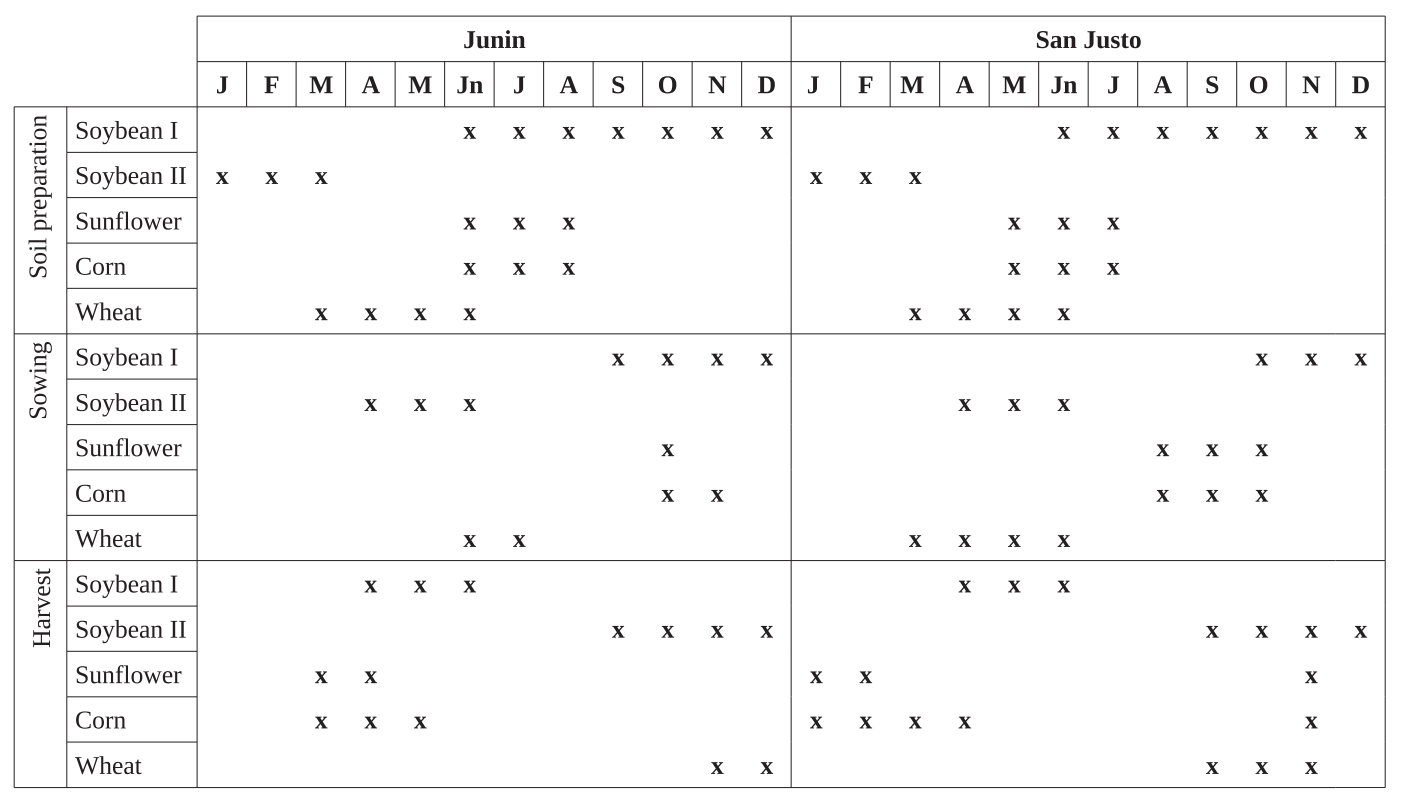

FIG. 2. Crop calendar for the four crops in Junín and San Justo.

soybean system (referred to as soybeanization ${ }^{1}$ ) (Pengue 2005, 2006; Hernández 2007; Caviglia and Andrade 2010). This process is encompassed by neoliberal policies implemented under President Carlos Menem (1989-99) and involves a biotechnological package (glyphosateresistant transgenic soybean and glyphosate) ${ }^{2}$ which, in association with the massive adoption of zero tillage (Garcia et al. 2000; Diaz-Zorita et al. 2002), reduces the cost of labor and overhead (fuel, equipment maintenance, etc.) and simplifies crop management (Caviglia and Andrade 2010).

Figure 3 shows a large increase in the total production of soybeans from roughly the mid-1980s in both districts, matching the positive trend observed at a larger scale (Viglizzo et al. 1997; Podestá et al. 1999; Magrin et al. 2005), while the three other crops are quasi-constant or decreasing. Overall, soybeans account for $75 \%-80 \%$ of the total production (and more than $85 \%$ of the total surface area) of the four crops at the end of the period. Production depends on surface area, not easily related to climate variability, and yields (Figs. 4a,b). The yield increase, clearest for maize, is due to overall technological improvements (mechanization and increased inputs)

\footnotetext{
${ }^{1}$ Soybeanization refers to the concentration of large areas on raising only one soybean crop.

${ }^{2}$ Glyphosate [N-(phosphonomethyl)glycine] is a broad-spectrum systemic herbicide used to kill weeds, especially annual broadleaf weeds and grasses known to compete with commercial crops grown around the globe.
}

and is not directly related to climate. The large increase in rainfall beginning in the 1940s that partially explains the multidecadal yield increase (Viglizzo et al. 1997; Magrin et al. 2005) is not seen at either site. Podestá et al. (2009) also showed that the long-term multidecadal increase in rainfall at Pergamino and Pilar (close in latitude to San Justo, but westward) is clear only before 1970 . From 1970 onward, the rainfall trend could not be considered a significant factor in explaining the yield increase (Figs. 4a,b)

The trend is adjusted by first removing a low-pass filtered (cutoff $=20 \mathrm{yr}$ ) time series. This is a better choice than a straight linear trend since the increasing annual rate tends to begin in the mid-1990s (Figs. 4a,b). The residuals from the low-pass filtered time series still contain some long-term increasing trend in variance. Therefore, we compute the interannual residuals as the ratio of the original time series to the low-pass trend at every point in time. This ratio (Figs. 4c,d) exceeds unity when the series is above the low-pass trend, and is below unity when the series is below the trend line. This approach tends to remove trends in variance that accompany trends in mean. We will focus our analysis on the interannual variations of yields.

The yield anomalies are variable over time among crops and districts (Fig. 4 and Tables 1-3, even though 2008-09 was a particularly "bad" year (Fig. 4). Overall, the correlations among crops for a single district are not significant at the $90 \%$ level except between maize and soybeans (Tables 1 and 2) when the long-term trend is 

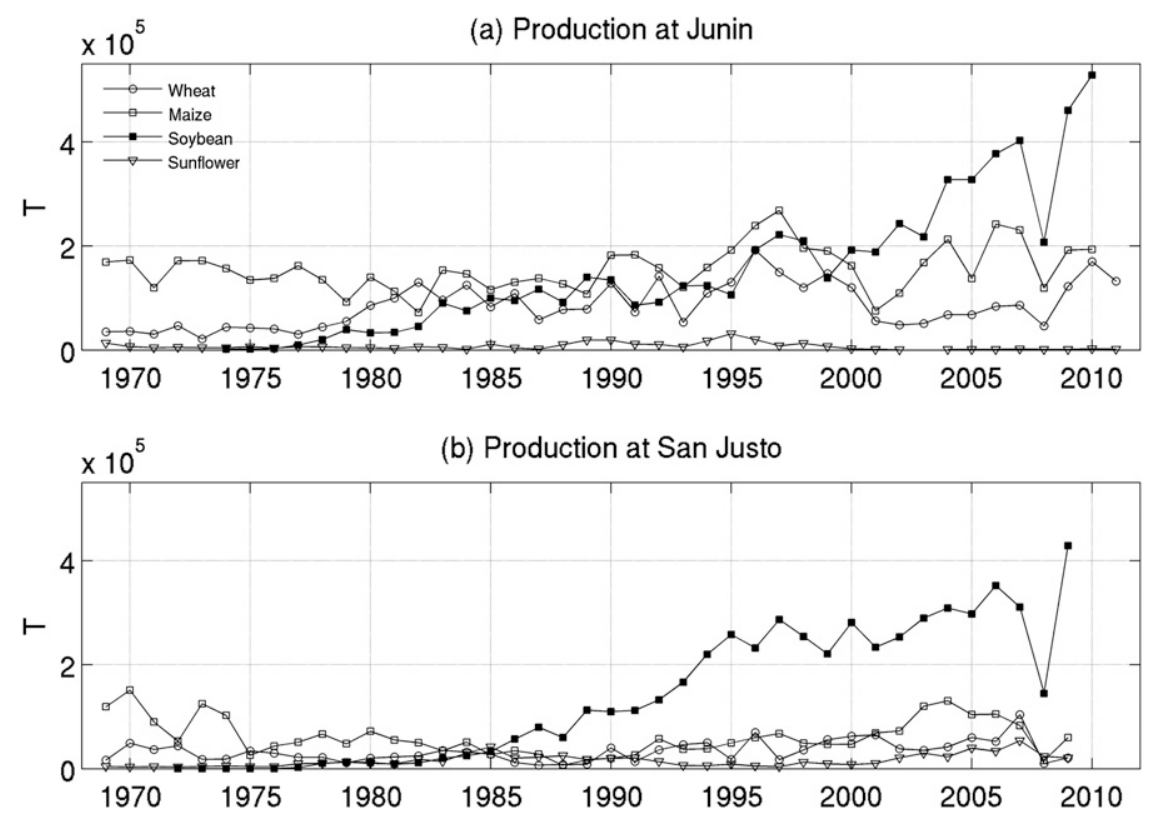

FIG. 3. Total production in metric tons of wheat, maize, soybean, and sunflower in (a) Junín and (b) San Justo. Production statistics were obtained from the Agricultural Estimates Division (SIIAP-MINAGRI) and National Institute of Agricultural Technology (INTA). Years in abscissa refer to January-December (wheat) and July-June+1 (other crops) seasons.

filtered out. The correlations between the same crops in Junín and San Justo are usually moderate $(17 \%-28 \%$ of common variance when the long-term trend is removed) except for wheat, which is lower (Table 3). This amount of common variance is similar to that of annual rainfall [from July to the following June (June +1)] in San Justo and Junín ( $r=0.53,26 \%$ of common variance).

Note that the ethnographic fieldwork (see section 3) was performed during years with highly different yields: the 2008/09 season was the worst, while the following 2009/10 season was one of the best for both districts and all crops (Fig. 4). From the climatic point of view, the extreme drought in 2008/09 (see section 4 and Fig. 11) was followed by above normal rainfall in 2009/10. On a larger scale, the 2009-12 period includes two neutral El Niño-Southern Oscillation (ENSO) years (2008/09 and 2011/12), a moderately warm (2009/10) ENSO event, and a cold (2010/11) ENSO event. We can thus hypothesize that the ethnographic fieldwork was not especially biased by near-constant climatic anomalies during the surveyed period, although participants' short-term experiences may play a role in their responses.

\section{Ethnological approach}

\section{a. Methodology}

The ethnographic analysis (Althabe 1990) consists of the researchers' long immersion (one year in each site) in the sociocultural field to be interpreted. During these long stays, we carried out a territorial scan and surveyed land use and tenancy data, residence of producers and landlords, rural infrastructure, etc. In parallel, we made observations and performed in-depth interviews with various local-scale stakeholders: small producers, agribusinessmen, local political authorities, and members of civil institutions (cooperatives, rural societies, nongovernmental organizations, etc.) in order to learn about local production activities and daily life in each rural town.

For this paper, a total of 79 interviews from the two locations (47 in Junín and 32 in San Justo) were made. Agriculture producers were asked to narrate their life history, how they organized their enterprises, their positive and negative experiences with climate events, and their strategies for mitigating each event. This allowed us to identify three different productive profiles (see section $3 b$ ). Based on these profiles, in order to understand the crop calendar and the relationships between each productive stage (crop spraying, sowing, harvest, etc.) and potential damaging climatic events (flood, drought, hail, frost, heat waves, etc.), we performed two surveys in July 2010 (a total of 26 and 28 interviews in San Justo and Junín, respectively) focused on the impacts of climate events on different types of agriculture production (dairy, livestock, cereals, oil seeds, etc.) and on the reconstruction of the local-scale agricultural calendar (Fig. 2). We designed a semistructured questionnaire, 
(a) Yields at Junin

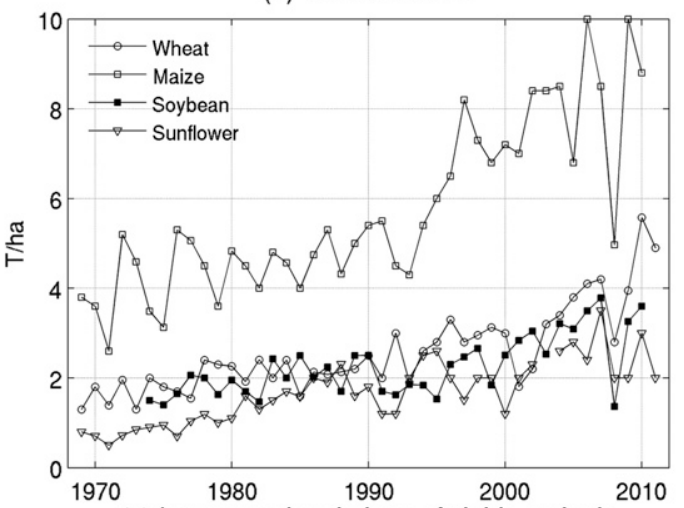

(c) Interannual variations of yields at Junin

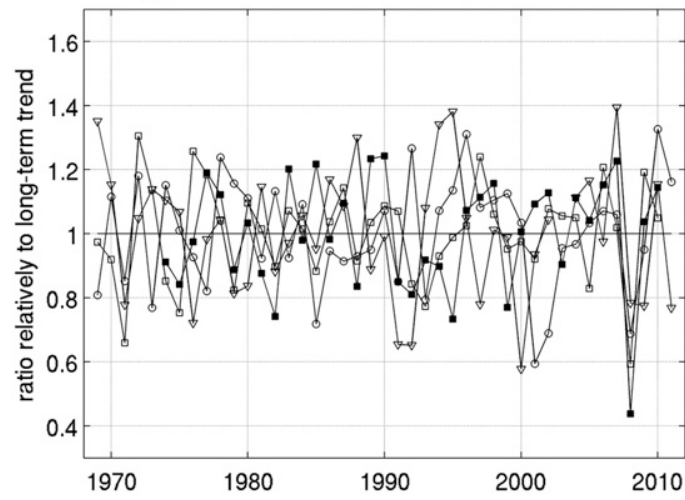

(b) Yields at San Justo

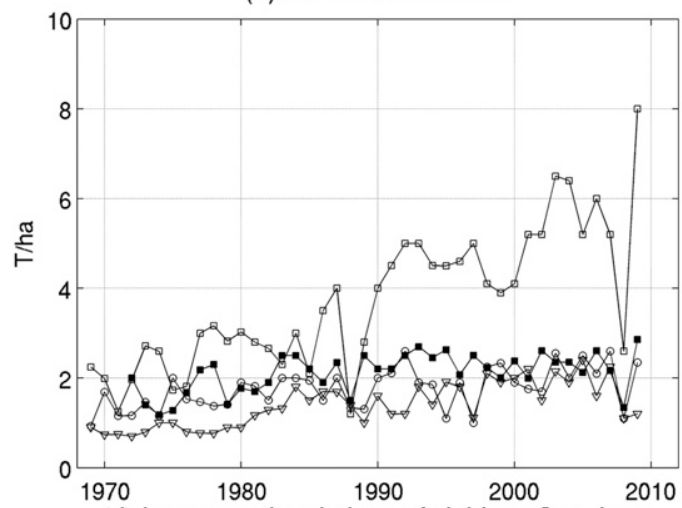

(d) Interannual variations of yields at San Justo

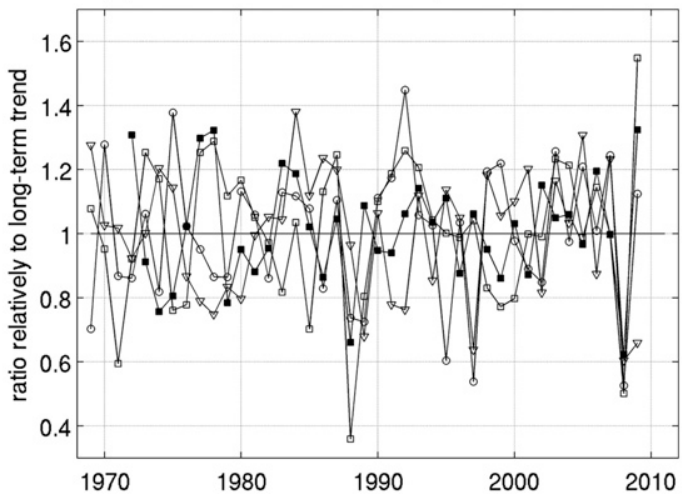

FIG. 4. Yields expressed as (a),(b) raw values (in tons per hectare) and (c),(d) interannual anomalies (as ratio between raw value and low-pass filtered yields $>20 \mathrm{yr}$ ) of wheat, maize, soybean, and sunflower in Junín and San Justo, respectively. Years in abscissa refer to January-December (wheat) and July-June+1 (other crops) seasons.

surveying the sown area, kinds of activities, major past climate events and their impact upon production, climate events of the ongoing cropping season, and strategies implemented to cope with the adverse climate events. The producers were also asked to identify the most significant adverse factor, not necessarily related to climate, impacting their activity. All answers were open without any predetermined response. Our posterior analysis grouped the most significant factor into general categories: climate, national policy, international market, etc.

Additionally, we performed two transsectorial participatory workshops (i.e., with different sectors of the community) in 2009 in San Justo and 2010 in Junín in order to address the different meanings of climate events for diverse productive profiles. A total of 15 individuals in San Justo and 25 in Junín participated, including agriculture producers, political authorities, NGO representatives, and researchers.

Using survey and workshop responses, we built a matrix codifying the answers per participant and climate event, combining cases in which the same person participated in both events to avoid duplicate responses. Figure 5 shows the frequency of answers for all climate events, as well as those related to other factors, when they account at least for $10 \%$ of the total of replies. Subsequently, in an integrative analytical stage, ethnographic material was paired with statistical and historical data (past yields for each region, local climate records, and climatic event records through mass media, etc.), allowing us to understand how each productive profile constructs meaning and representation from climate (see section 3b and Fig. 6). We characterized and analyzed the sensitivity of diverse productive profiles and strategies (see section $3 \mathrm{~b}$ and Fig. 6) to coping with climate variability. In sum, throughout the research

TABLE 1 . Correlations $(\times 100)$ between raw (under the diagonal) and high-pass filtered $<20 \mathrm{yr}$ (above the diagonal) yields in Junín. One, two, and three asterisks indicate significant values at the twosided $90 \%, 95 \%$, and $99 \%$ level according to a random-phase test (Janicot et al. 1996; Ebisuzaki 1997).

\begin{tabular}{lllcc}
\hline & Wheat & Maize & Soybean & Sunflower \\
\hline Wheat & & 14 & 1 & 4 \\
Maize & $76^{* * *}$ & & $60 * * *$ & 0 \\
Soybean & $66^{* * *}$ & $82 * * *$ & & 10 \\
Sunflower & $69 * * *$ & $66 * * *$ & $64 * * *$ & \\
\hline
\end{tabular}


TABLE 2. As in Table 1, but for San Justo.

\begin{tabular}{lllcc}
\hline \hline & Wheat & Maize & Soybean & Sunflower \\
\hline Wheat & & $25^{*}$ & 11 & $27 *$ \\
Maize & $57 * * *$ & & $49 * * *$ & -6 \\
Soybean & $35^{* *}$ & $65 * * *$ & & -17 \\
Sunflower & $59 * * *$ & $59 * * *$ & 38 & \\
\hline
\end{tabular}

process, we analyzed the social livelihood shared by each rural community. This ethnological approach allowed us to understand climate events' meanings and the ways in which respondents engage them through their respective productive practices, as well as keeping a record of their vulnerabilities and mitigation strategies.

\section{b. Climate representations and socioproductive profiles}

Based on interviews and our own observations, we were able to identify three socioproductive profiles: agribusiness and capitalized and noncapitalized farmers. Agribusiness participants (32\% of the sample in Junín and $50 \%$ in San Justo) cultivate a large area (usually $>1000$ ha), owned or rented, possibly spread over several different regions or even countries (i.e., Brazil, Paraguay, Uruguay, and Bolivia), and are thus able to sustain geographical and crop diversity, mitigating climate risks on the local scale (e.g., hail) or regional scale (e.g., flood or drought). These participants are directly connected to the international markets (mainly for soybeans) and organize their business through a network allowing them to control many factors (e.g., land renting/occupation, third-party labor, professional and expert boards). Additionally, they are able to negotiate prices at each stage of the production chain (agro-chemical suppliers, exporters, etc.) and can improve raw production (soybean oil and flour, pellets for livestock, agrochemical retail, grains stock, transport, etc.), generating strategic agreements with other commercial, financial, and technological companies (biotechnology, informatics, and agriculture machinery). This allows these individuals to build large-scale transsectoral businesses.

Capitalized farmers ( $46 \%$ of the sample in Junín and $12 \%$ in San Justo) cultivate around 500-800 ha and may also rent lands to increase their production scale, but they tend to remain within the district (i.e., their rented lands are generally near an inherited nucleus). Their capitalization is mostly based on agriculture machinery, which they use on their own lands, as well as for agricultural services contracts to ensure higher profitability. Their production is directed toward both international and national markets (e.g., milk, meat).

Finally, noncapitalized farmers (21\% of the sample in Junín and 38\% in San Justo) organize their production
TABLE 3. Correlations $(\times 100)$ between yields in Junín and San Justo. The high-pass filtered yields are computed as the ratio between the raw yields and the low-pass filtered yields $>20 \mathrm{yr}$ estimated through a Butterworth recursive filter. One, two, and three asterisks indicate significant values at the two-sided $90 \%, 95 \%$, and 99\% level according to a random-phase test (Janicot et al. 1996; Ebisuzaki 1997).

\begin{tabular}{lcc}
\hline \hline & Raw yields & High-pass filtered yields \\
\hline Wheat & $57 * * *$ & 21 \\
Maize & $84 * * *$ & $42^{* * *}$ \\
Soybean & $53^{* * *}$ & $52^{* * *}$ \\
Sunflower & $80^{* * *}$ & $53 * * *$ \\
\hline
\end{tabular}

exclusively on their own lands since the current increase in land rental prices excludes them from the real estate market. Most of the properties are smaller than 200 ha. These farmers may or may not hire third-party servicesagriculture machinery is usually too expensive to purchase, so they manage old or refurbished mechanical equipment-and their production is directed mostly to subsistence and local markets (local and regional fairs). Neither capitalized nor noncapitalized farmers have the capacity to really negotiate various inputs, supplies, and third-party services. Their fixed costs are thus usually much higher than those of agribusiness (Hernández et al. 2013a,b).

The percentages referred to above for each profile correspond to what is observed in the mean in both districts. In other words, the overall structure is less homogeneous in San Justo than in Junín. Among the three profiles, two of the factors that determine the organization of a farm show a high sensitivity to climate: 1) the overall level of capitalization, including the number and sophistication of agricultural machinery, and 2) the total area cultivated, allowing diversification of crops/varieties and of the crop calendar, so that some of adverse climate events could be potentially mitigated.

The answers are ranked into four general categories: climate (mostly rainfall variability and extremes), international markets, national policy and regulation, and cost of production and credit (Fig. 5). Climate is clearly the most important adverse factor in Junín, while international markets, production costs, and national policy appear to be as important as some climate factors in San Justo. Eight different climate factors are indexed in San Justo versus 6 in Junín. Drought and flood (and rainfall variability in San Justo) are clearly the most frequent adverse climate factors, more so than frost, extreme temperature, and hail. The $20 \%$ of producers citing bad drainage of the Salladillos sector in San Justo (Fig. 1c) also mention flooding. The El Niño effect is cited as a specific factor in San Justo only. This sensitivity fits well within the larger amplitude of the ENSO response (i.e., 
(a) Junin

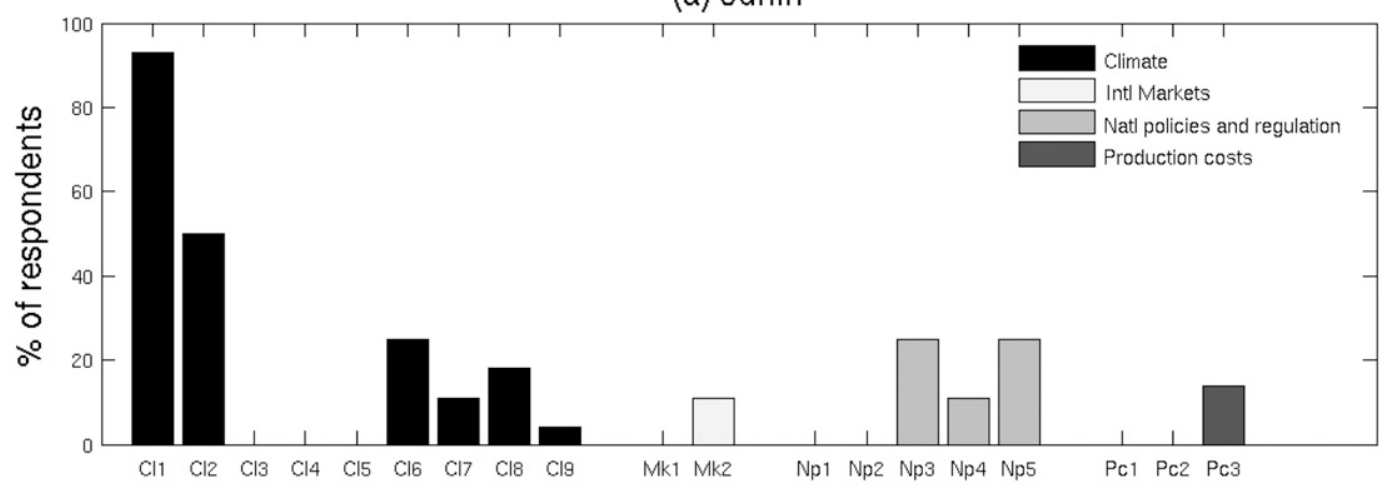

(b) San Justo

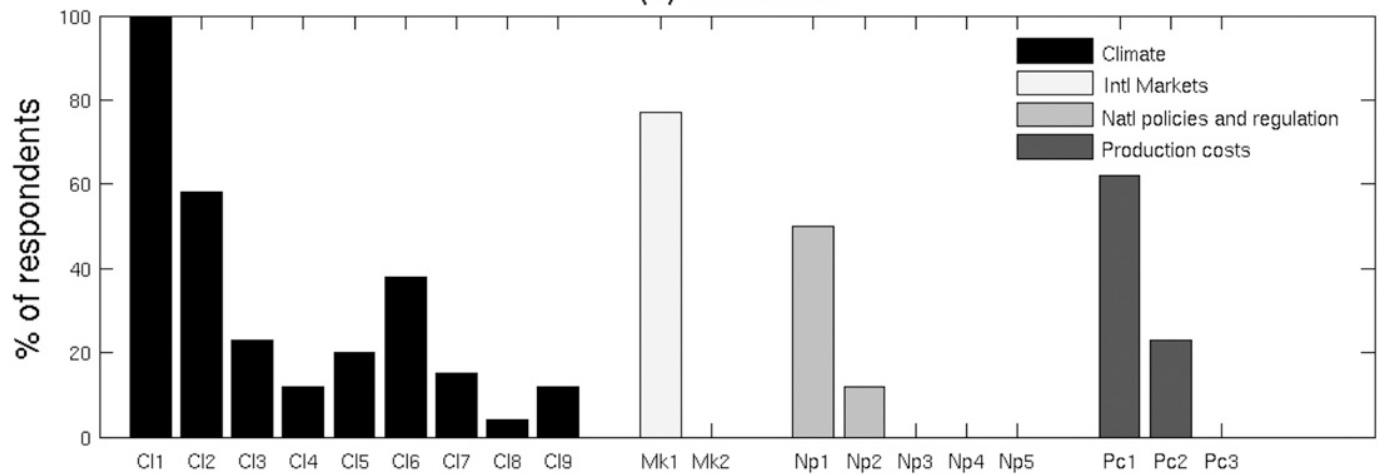

FIG. 5. Percentage of different factors having an adverse effect on farming systems according to producers (based on surveys and transectorial workshops only; the people being interviewed during both events are counted just once; see text) in (a) Junín and (b) San Justo. The number of invoked factors is unlimited and the answers are open. All factors related to climate are indicated while the other factors are shown only if their percentage $>10 \%$. Climate factors (prefix "Cl") refers respectively to those roughly related to 1$)$ rainfall variations ["Drought" $(\mathrm{Cl1})$, "Flood" $(\mathrm{Cl} 2)$, "Rainfall variability" $(\mathrm{Cl} 3)$, "El Niño effect" (Cl4), "Bad drainage of Salladillos sector" (Cl5)], 2) temperature extremes ["Frost" (Cl6) and "Extreme temperatures" (Cl7)], and 3) other extremes ["Hail" (Cl8) and "Strong Winds" (Cl9)]. Factors related to international markets and exportation (prefix "Mk") denote "International market pressure" (Mk1) and "Exportation closure." Factors related to national policies and regulation (prefix "Np") denote "Conflicts with national authorities" (Np1), "Absence of public policies adapted to local producers" (Np2), "Deficiency of farming policy (dependent on the economy policy)" (Np3), "Lack of land use laws/policies" (Np4), and "Retention/state intervention in the market" (Np5). Finally, factors related to production costs and credits (prefix "Pc") denote "Production costs" (Pc1), "Lack of availability of agriculture machinery" (Pc2), and "Lack of funding and credits for agriculture sector" (Pc3).

negative/positive rainfall anomalies during cold/warm ENSO events) in the central-north sectors of the Argentinean Pampas (Messina et al. 1999; Podestá et al. 2002). The fact that frost is more frequently cited at the warmer location ( $38 \%$ vs $25 \%$ ) could be related to the greater impact of negative temperature there.

The exposure of agriculture to climate variability depends on the occurrence of each climatic event during the agricultural calendar (i.e., soil preparation, sowing, spraying, and harvesting), the different crop stages, and on the three productive profiles defined above. We observe that the sensitivity to drought and flood expressed by these three kinds of producers (except for noncapitalized farmers) is more or less similar to that of the overall regions (Figs. 5 and 6).
These results were combined with qualitative interviews and contextualized within particular productive practices and strategies for facing climate events, according to each respondent's socioproductive profile. As a result, we found the significance of climatic events is unique to each socioproductive profile (i.e., the same climate event is experienced differently according to each person's material and symbolic resources). Below, we detail how the same climate event is integrated within the socioproductive strategies of the three farmer profiles.

\section{c. Strategies and vulnerabilities per socioproductive profile}

The agribusiness profile defines floods as a serious threat (Fig. 6), but if the flood is moderate and occurs 
(a) Agri-business

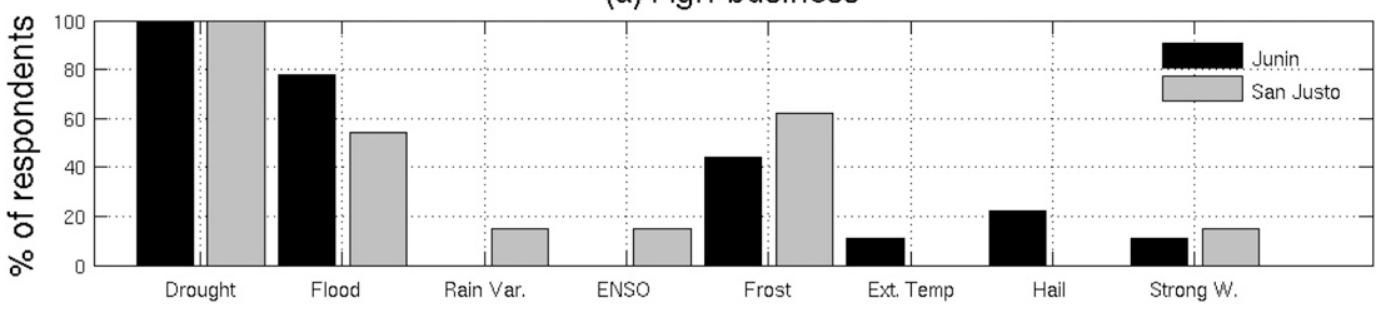

(b) Capitalized Farmers

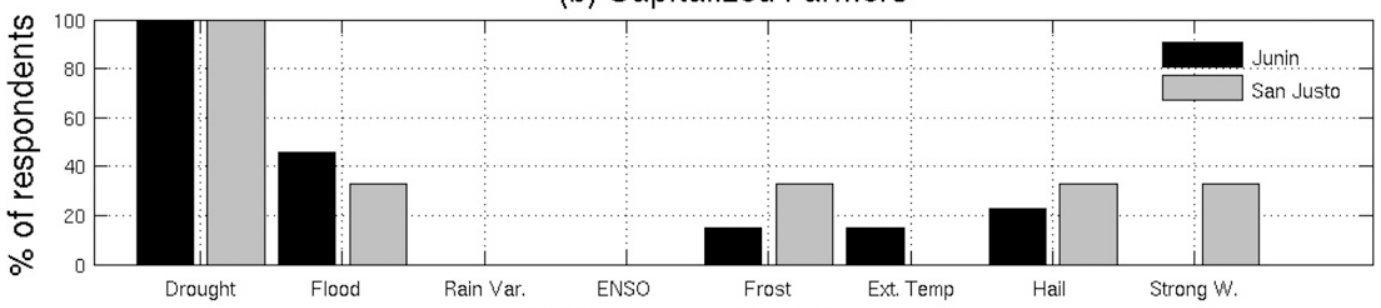

(c) Non-capitalized Farmers

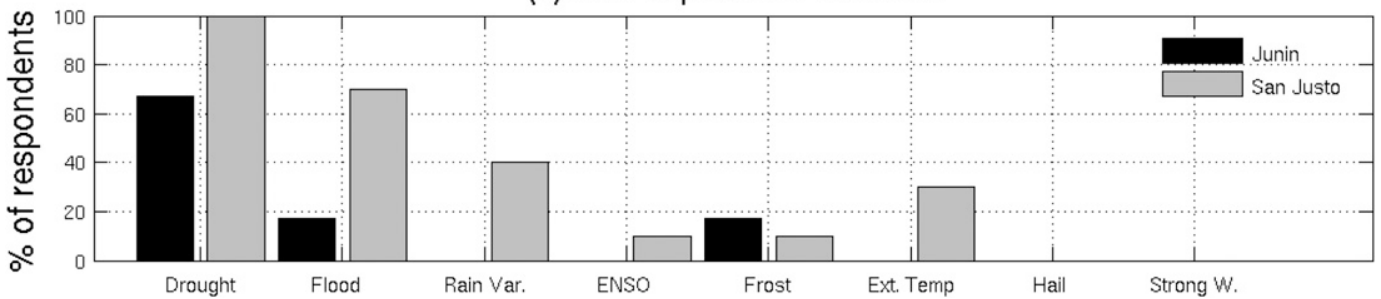

FIG. 6. Percentage of adverse climatic factors according to the three profiles of producers defined in section $3 \mathrm{~b}$ (based on surveys and transectorial workshops only; the people being interviewed during both events are only counted once; see text). The number of invoked climatic factors is unlimited and the answers are open.

near the end of the crop cycle, agribusinesses can use double traction machines for harvesting, and a new technology (plastic bag storage) allows them to store wet harvests. In case of long-lasting floods (at least several consecutive weeks or even months), crops are damaged, but agribusiness producers (and in some cases, capitalized farmers) are able to diversify their crops in different geographical areas to buffer economic losses.

Another strategy against flooding common to agribusiness and capitalized farmers is to build private channels, draining the excessive water outside their productive fields:

Due to the nature of my field-it is a low field-it suffers excessive rainfall a lot. It has experienced 1993 floods badly, and afterwards it went through 2000 and 2002 floods too. It has been channelled. It is to take out the exceeding water ... it was approved by the Municipality (Agronomic engineer and capitalized farmer, Junín, 2010).

In most cases, noncapitalized farmers cannot afford such drainage, and this specific mitigation strategy could increase their vulnerability to floods. In case of ENSO events, agribusiness and capitalized farmers may reschedule the sowings and harvests, as well as taking into account technical advice from climate experts and agronomists:

Now we are in front of a "niña" we are doing some practices to not leave weeds, to conserve all water as possible, because to sow wheat, if we don't have $150 \mathrm{~mm}$ accumulated ... it is very difficult. Luckily, this year, in the fields with good water penetration, we reached $300 \mathrm{~mm}$, but in the regular fields, we have $150 \mathrm{~mm}$... We have postponed sowing since they [the National Meteorological Service] say that rain could be late this season, and perhaps, before the filling of the grain is completed we can have some water... But for this, we have to have a very well made plant, very well fed ... We are applying fertilizer doses, some quite high. We are anticipating! (Capitalized farmer, San Justo, 2010)

To cope with drought, agribusiness farmers rely mostly upon productive and geographic diversification, and on the flexibility of their agricultural calendar (e.g., different crop varieties or cycles):

I planted what I thought necessary to cover the costs ... It is a very important issue that we need to think about, because we have the cattle and the calves, but we also need the rain, because if you have the cow, you need the grass, and if not, you can give them corn ... there are alternatives. In 
livestock you have more alternatives than in agriculture... Except for irrigation ... the intelligent corn that will be released now in the United States, that grows lower or higher from the root and it will support the droughts ... but that is only concerning corn ... (Agribusiness farmer, San Justo, 2009)

With regard to frost and hail, calendar flexibility and the use of transgenic crop varieties are frequent strategies within the agribusiness profile, but most producers get crop insurance since losses are unavoidable.

Frosts have influenced sowing dates this year. In my exploitation, I had almost all corn plots sown after October 10th to avoid any problems or inconvenience. (Agribusiness farmer, Junín, 2010)

I remember when I was a child, we sowed corn, sunflower on September 21st, now we sow ... on August 10th ... August 5 th ... because we found that it does not freeze due to the improvement of the seeds ... And this also allows you to crop a soybean that we call "soybean III" [i.e. three soybean crops in a year]. (Agribusiness farmer, San Justo, 2009)

The main strategies that capitalized farmers employ to cope with drought are traditional diversification (i.e., increasing livestock if possible), supplies saving (which implies omitting or shortening soil preparation), and pluri-activity (as with third-party services for agribusiness). This last strategy is critical since it increases their income and buffers yield losses.

If you are pressed by drought when harvesting, [then] you are lost. Because you lose the harvest (...). [Instead] Dairy will force you to give grass to the animals. You'll have a serious problem because, how are you going to feed the animals? [If you don't have grass.] But you can buy it elsewhere. One way or another, even though if it is not economically correct, because it can lead you to a terrible economic decline, you will be able to maintain the cow with something. For 3, 4, 5, 6 months, you will be down, but then you'll return to your normality. The difference with agriculture is that you will be lost until the next year! (Capitalized farmer, Junín, 2010)

When flooding occurs, this profile needs to move livestock to higher lands. Nevertheless, as previously mentioned, these farmers may also afford private channels to drain at least some of the excessive water. ${ }^{3}$ Like the agribusiness profile, capitalized farmers use plastic bags to store wet grains/seeds. The situation is different during the ENSO cycle, and when there is frost and hail-their sowing and harvesting dates are less flexible:

\footnotetext{
${ }^{3}$ Although this is a frequent strategy, most of these channels were done without municipal authority approval.
}

This last year, frost and drought were something that was more or less expected, and we couldn't escape because the drought was very long and, even if one hurried to plant the corn, sooner or later, in the long term, frost would burn it. So, I planted last year in an average date: October 5th to 10th. Frost combined with drought affected it. (Capitalized farmer, Junín, 2010)

Additionally, any flexibility is compromised when farmers are partly bound to the dates arranged with agribusiness producers, who as third-party services contractors restrict their machinery availability for their own work. As this capitalized and contract farmer explains, despite being out of the regular sowing and harvesting dates, he had to run the risk and proceed:

As we saw later, the harvesting date will be postponed, and we should expect flowering and everything later, but that is why [the crops] are more susceptible to frosts. And that may generate another loss, another problem, but we started anyway. (Capitalized farmer, San Justo, 2009)

Noncapitalized farmers do not own their no-tillage machinery and thus depend on agricultural services companies for spraying, seeding, and harvesting, restricting their flexibility to modifying their agriculture calendar in case of an extreme climatic event. This makes their livelihoods more vulnerable and highly dependent on their ability to plan the agriculture system as a whole. For example, in case of a drought near the start of the crop season, the noncapitalized farmers could simply delay sowing until enough rainfall has moistened the upper soils:

If [the National Meteorological Service] announce bad weather I can't do anything; for some crops we have to decide. For example, I could not sow wheat in August because it will grow in temperatures that wheat does not support, then I choose not to sow. I could not sow corn in October because it will flower in the summer, on early January or late December, then we need to have rain every 3, 4 days at that time. If that is not forecast, sowing is not convenient. (Noncapitalized farmer, San Justo, 2009)

Last year I left land without sowing, since sowing without any rain is in vain. And rainfall came at the end of January, then we sowed and we did ok, but that was a coincidence. (Noncapitalized farmer, Junín, 2010)

In this sense, the dependence upon rainfall variability is extreme. The same happens with floods and a frequent answer is "there is nothing we can do" since the noncapitalized farmers cannot afford private channeling and usually suffer from arbitrary and disordered channels built by their neighbors (capitalized and agribusiness farmers). Finally, in the case of ENSO events, frost, and hail, these farmers are excluded from the climate services market (insurance companies, professionals, etc.) and their only choice is to refer to 
(a) Rainfall vs yield (wheat)

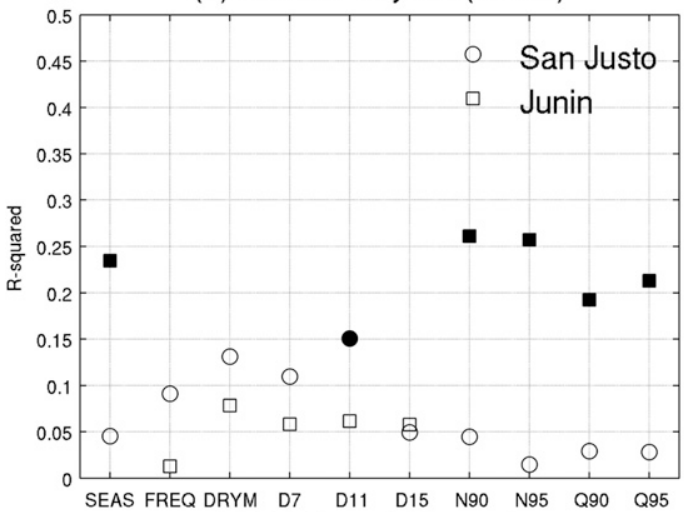

(c) Rainfall vs yield (soybean)

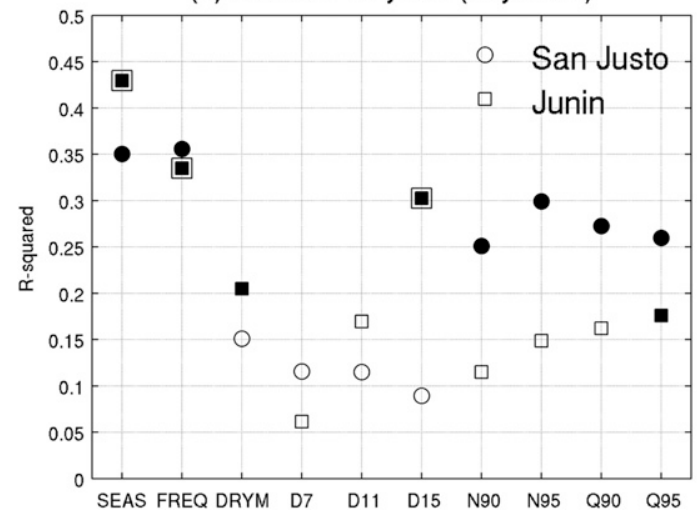

(b) Rainfall vs yield (maize)

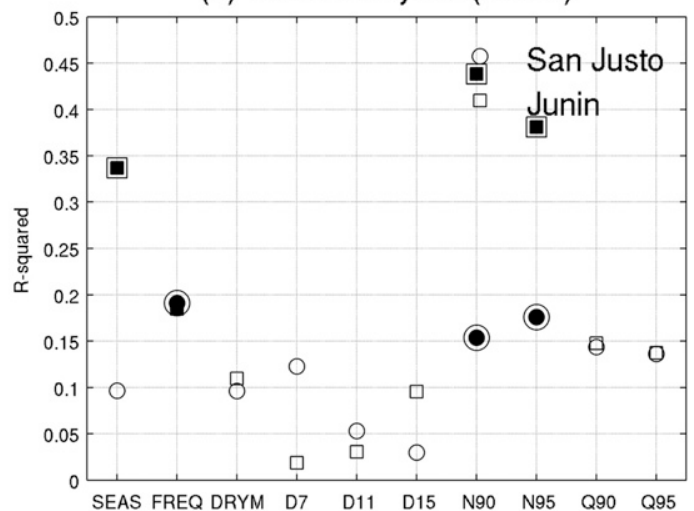

(d) Rainfall vs yield (sunflower)

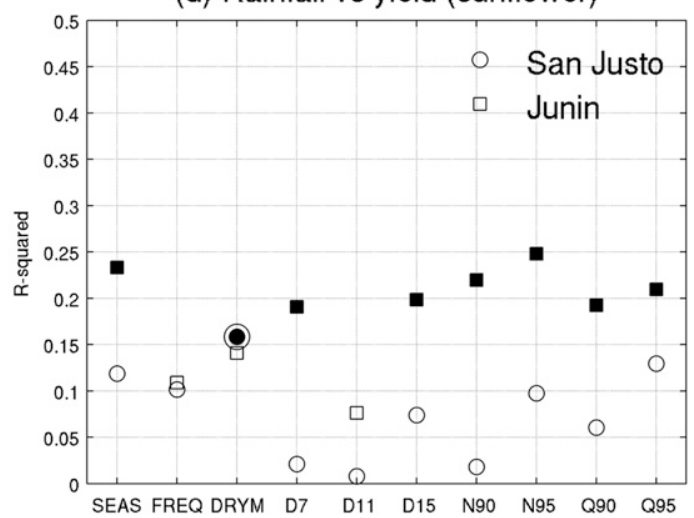

FIG. 7. Explained variance by a univariate quadratic regression (see appendix) with rainfall variables (on the abscissa) as predictor and yield [of (a) wheat, (b) maize, (c) soybean, and (d) sunflower] as response. The rainfall variables are computed on 1 July of year $(-1)$ to 30 June of year (0) except for wheat (from 1 January to 31 December). SEAS is the amount of rainfall. FREQ is the number of wet days $\geq 1 \mathrm{~mm}$. DRYM is the mean length of the dry spells (=consecutive days receiving less than $1 \mathrm{~mm}$ ). D7, D11, and D15 are the total number of days included in a dry spell lasting at least 7,11, and 15 days, respectively. N90 and N95 are the total number of days $\geq 90$ th and 95th percentile while Q90 and Q95 are the rainfall received during these days. A filled symbol indicates that the variance explained by the quadratic regression is significant at the $90 \%$ level (according to an $\mathrm{F}$ test) while a double symbol indicates that the quadratic term is significant at the $90 \%$ level (according to a Student's $t$ test). It is displayed only when the variance explained by the quadratic regression is significant at the $90 \%$ level (according to an F test). Daily rainfall is obtained from the National Meteorological Service and the National Institute of Agricultural Technologie (INTA).

traditional knowledge based on the observations of several generations of producers.

In summary, the strategies used by each socioproductive profile suggest that agribusiness and capitalized farmers have a better capability to prepare successful responses. Noncapitalized farmers have no geographical, technological, or commercial flexibility at all, and are thus directly exposed to climatic shocks. Their traditional strategy for diversifying risks is to combine agriculture with dairy production and/or livestock. But dairy production is also very vulnerable since milk production decreases in case of flood and drought. Extreme high temperatures, combined with a water deficit, also threaten calving in spring and summer. In the case of breeding stock, cows and feeding pastures are exposed during drought and floods. The variability of these strategies indicates that climate events, which have discrete scientific definitions, are considered very differently by the farmers depending on how each adverse event interacts with other factors of their socioproductive system. Thus, it is important to consider the social significance of each climate event to identify socially relevant scientific knowledge for each category of farmer.

\section{Relationships between yields and climate variability}

\section{a. Annual relationship between yields and climate}

The first analyses consider the annual rainfall mean (Fig. 7) and temperature (Fig. 8) characteristics with the interannual yield variations defined in section 2. Here we considered the annual values from January to December 
(a) Temperature vs yield (wheat)

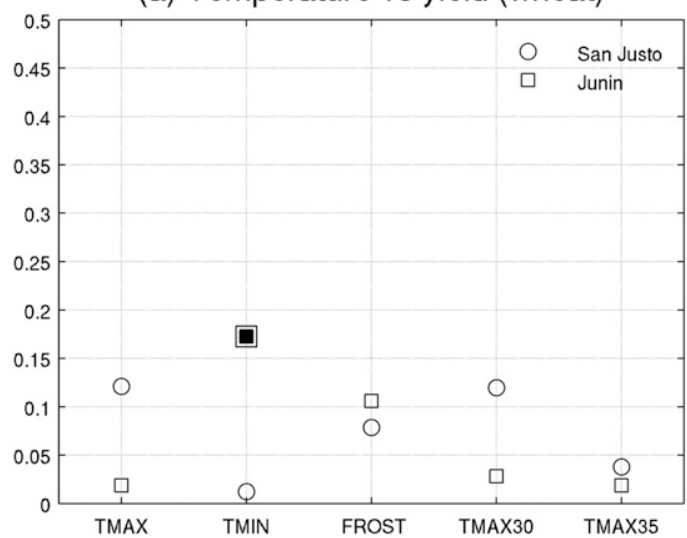

(c) Temperature vs yield (soybean)

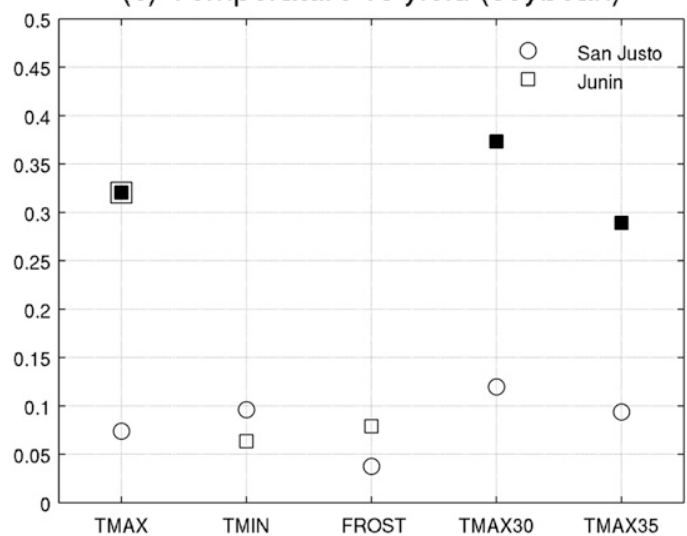

(b) Temperature vs yield (maize)

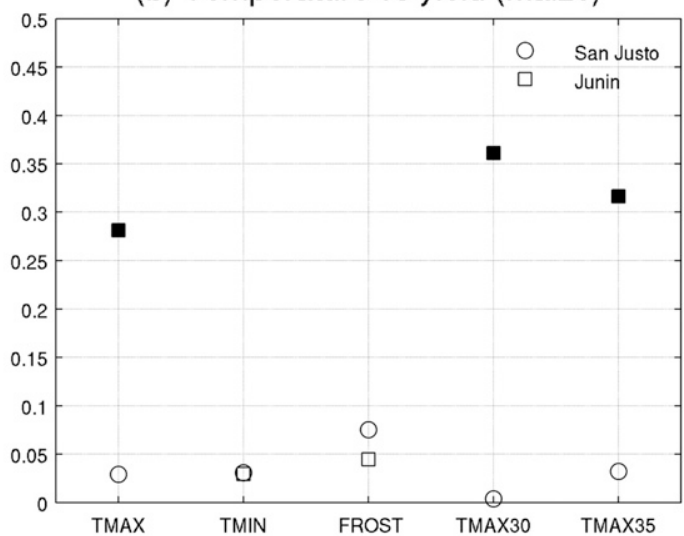

(d) Temperature vs yield (sunflower)

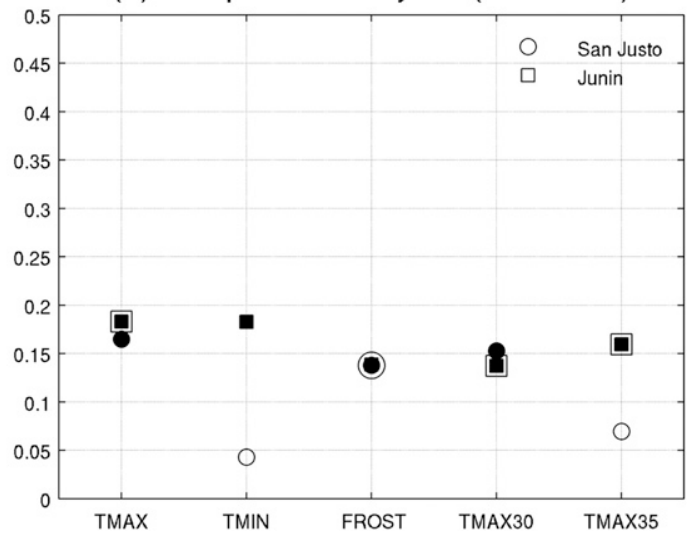

FIG. 8. Explained variance by a univariate quadratic regression with temperature variables (abscissa) as predictor and yield [of (a) wheat, (b) maize, (c) soybean, and (d) sunflower] as response. The temperature variables are computed on 1 July of year (-1) to 30 June of year (0) except for wheat (from 1 January to 31 December). TMAX is the mean maximum temperature. TMIN is the mean minimum temperature. FROST is the number of days with minimum daily temperature $\angle=0^{\circ} \mathrm{C}$. TMAX30 and TMAX35 are the number of days with maximum daily temperature $\geq 30^{\circ} \mathrm{C}$ and $\geq 35^{\circ} \mathrm{C}$. A filled symbol indicates that the variance explained by the quadratic regression is significant at the $90 \%$ level (according to an $\mathrm{F}$ test) while a double symbol indicates that the quadratic term is significant at the $90 \%$ level (according to a Student's $t$ test). It is displayed only when the variance explained by the quadratic regression is significant at the $90 \%$ level (according to an $\mathrm{F}$ test). Daily rainfall and minimum/maximum temperature are obtained from the National Meteorological Service and the National Institute of Agricultural Technologie (INTA). As temperature was not available for San Justo, we considered the record at INTA-Rafaela, almost $70 \mathrm{~km}$ southwest of San Justo, as a good proxy since the topography is similarly flat between both stations without any significant difference in altitude. The daily temperature at Rafaela is missing from 1 March 2007 to 31 December 2007 and is not replaced here.

for wheat, and from the start of July until the following June for maize, soybean, and sunflower (Fig. 2). In this latter case, 2008 refers to the year from July 2008 to June 2009. Note that we could not separate the two possible soybean harvests. Figure 7 shows the $R^{2}$ value of a quadratic function (see appendix) using rainfall variables as predictors and yields of the four crops as predictand. Our main goal is to compare farmers' social representations of the climatic risks and climate impact on yields. We saw in section 3 that farmers ranked drought first, and then flooding, as the main adverse climatic risks. Drought is a complex concept and its definition and exact threshold are somewhat arbitrary. Climatologists usually define drought as a cumulative deficit of rainfall relative to the local mean (Byun and Wilhite 1999; Keyantash and Dracup 2002), but this could be defined either at intra-annual time scales (e.g., a dry spell of $N$ consecutive days receiving less than $1 \mathrm{~mm}$ of rainfall) or at interannual time scales as an overall seasonal deficit under a given threshold. Moreover, a given 10-day dry spell may not have the same impact if it occurs just after sowing or during the maturation stage.

The mean length of dry spells (throughout the year) equals 6.6 days in Junín and 7 days in San Justo. 
Agronomists also consider the amount of rainfall stored in the upper levels of soils. We expect that farmers have also a different, and perhaps more comprehensive, view (Meze-Hausken 2004); they consider any short-term (but occurring at a critical stage of the crop development) or long-term (from seasons to multiple consecutive years) deficit of rainfall leading to economic and social problems to be drought. A flood may be less ambiguous, especially in the tropics where wet spells are usually short (typically lasting between a few hours and 2 days when a single daily recording is used). In that context, a flood may be easily associated with an extreme daily rainfall event, that is, above the 90th percentile (38.3 $\mathrm{mm}$ in San Justo and $35 \mathrm{~mm}$ in Junín) or the 95th percentile $(50.8 \mathrm{~mm}$ in San Justo and $47.4 \mathrm{~mm}$ in Junín) of wet days (i.e., days receiving at least $1 \mathrm{~mm}$ of rainfall). The mean length of wet spells equals 1.5 days in Junín and 1.6 days in San Justo. Even smooth, but cumulative, positive rainfall anomalies could lead to a damaging flood without any daily events above the 90th or 95th percentiles.

As drought and flood cannot be strictly and uniquely defined, in the following analysis we use several indices either at the annual (section 4a) or at intra-annual scales (section $4 \mathrm{~b}$ ). The rainfall amount (RA) is the most integrative characteristic able to monitor short- to longterm excess or deficit of rainfall. We also compute the mean length of dry spells (DRYM) and the number of days in dry spells lasting at least 7 (D7), 11 (D11), and 15 (D15) consecutive days. For characterizing floods, we compute the number of days equal to and above the 90th percentile of wet days (N90) and the amount of rainfall received during these days $(\mathrm{Q} 90)$. The same is done with the 95th percentile (N95 and Q95). For temperature, we consider mostly the mean, TMAX and TMIN, but also the number of frost days (FROST hereafter with TMIN $\leq$ $0^{\circ} \mathrm{C}$ ) as well as the number of days with a maximum temperature $\geq 30^{\circ} \mathrm{C}(\mathrm{TMAX} 30)$ and $\geq 35^{\circ} \mathrm{C}$ (TMAX35). Remember that the rainfall risks perceived by farmers suggest a nonlinear relationship broadly associating anomalously positive and negative rainfall with low yields.

The $R^{2}$ value is low and usually not significant at the $95 \%$ level for wheat (Fig. 7a), suggesting a weak sensitivity to rainfall variability, which is consistent with previous analyses (Podestá et al. 1999; Letson et al. 2001; Magrin et al. 2005). For the other three crops, $R^{2}$ is usually larger, especially in Junín (Figs. $7 b-d$ ). The yields' sensitivity to rainfall, and hence water availability, fits well with the previous analyses of Magrin et al. (2005) over a larger area. The largest explained variance is usually observed for the most integrative variablethe annual amount of rainfall-but N90 and N95 could be also significant (Fig. 7). The quadratic term is more frequently significantly different from zero in Junín than in San Justo (Fig. 7).

Figure 8 presents the results using annual temperature characteristics. Note that $R^{2}$ is almost never significant at the $95 \%$ level at the warmest location (Rafaela/San Justo), suggesting a weak sensitivity of crops to temperature, whereas $R^{2}$ is frequently significant in Junín. This would be expected if the main threat is related to cold temperatures, but the most important variables at Junín are then the frequency of hot and very hot days with the mean maximum temperature (Fig. 8). In the following, we focus on rainfall since the farmers emphasized this variable.

Figure 9 shows scatterplots of the interannual variation of yield and the annual rainfall in Junín with the quadratic fit. Maize (Fig. 9b) and soybean (Fig. 9c) reflect, at least partly, the farmers' perception that low yields could be related either to dry years (as in 2008) or wet years (e.g., 1992). But even in this case, drought is more critical than floods and the highest yields are associated with weak above-normal anomalies (Podestá et al. 1999). The scatterplot also confirms the relative absence of a relationship between annual rainfall and wheat yields (Fig. 9a), and similar annual amounts (as in 2001 and 1992) could lead to contrasting yields. The sunflower crop is also different from maize and soybean cases with an almost linear relationship: the highest yields are correlated with negative rainfall anomalies (Magrin et al. 2005), still with a large spread and saturation of the positive effect for very dry years.

The scatterplot for San Justo (Fig. 10) confirms weaker relationships than for Junín. The relationship between annual rainfall and wheat yield is very weak; dry or near-normal years could be associated with contrasting yields, even if 2008 (a very dry year) resulted in extremely low yields (Fig. 10a). The other crops indicate a near-linear positive (maize and soybean; Figs. 10b,c) and negative (sunflower; Fig. 10d) relationship, but with a large spread, especially for dry and near-normal years.

The data from both Junín and San Justo also give great weight to the 2008 season, which combined extreme drought with very low yields for the four crops. Recomputing the regression between interannual yield variation and annual rainfall without the 2008 season (Table 4) decreases the explained variance for almost all crops (except for sunflower), but its significance is basically unchanged and the relative impact of annual rainfall on crop is not critically modified.

\section{b. Subseasonal modulation of rainfall/temperature anomalies related to yields}

The previous section suggests that the climatic risks perceived by farmers fit well with the observed relationship 
(a) $\mathrm{Rsq}=23 \%$ (F-test $=99 \%) \mathrm{T}$ test $(\mathrm{Q}$ term $)=90 \%$

(b) Rsq $=34 \%(F$-test $=100 \%)$ T test $(\mathrm{Q}$ term $)=100 \%$

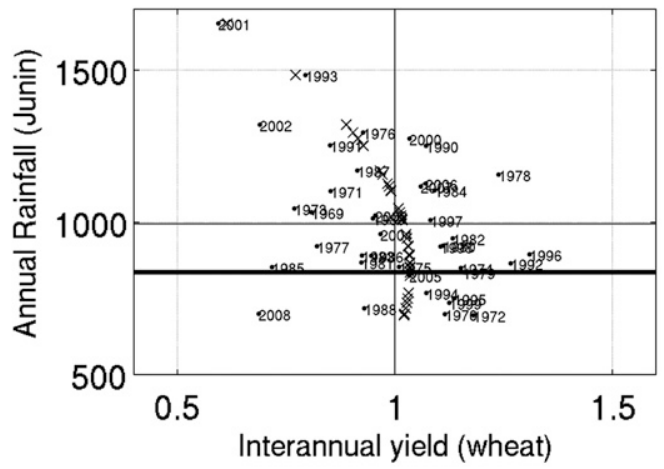

(c) $R s q=43 \%$ (F-test $=100 \%)$ T test $(Q$ term $)=100 \%$

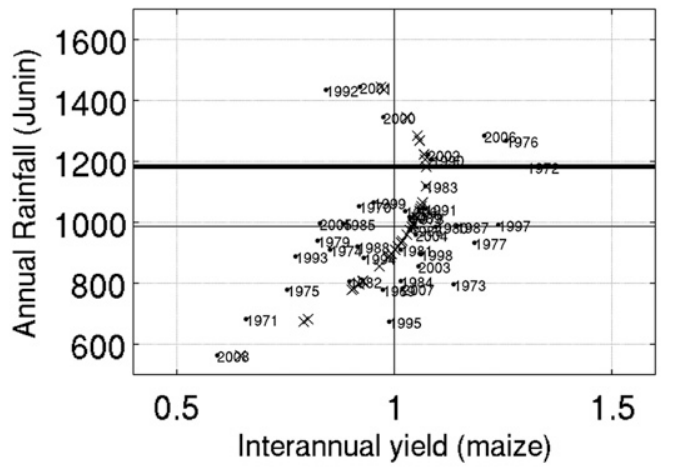

(d) $\mathrm{Rsq}=23 \%$ (F-test $=99 \%) \mathrm{T}$ test $(\mathrm{Q}$ term $)=89 \%$
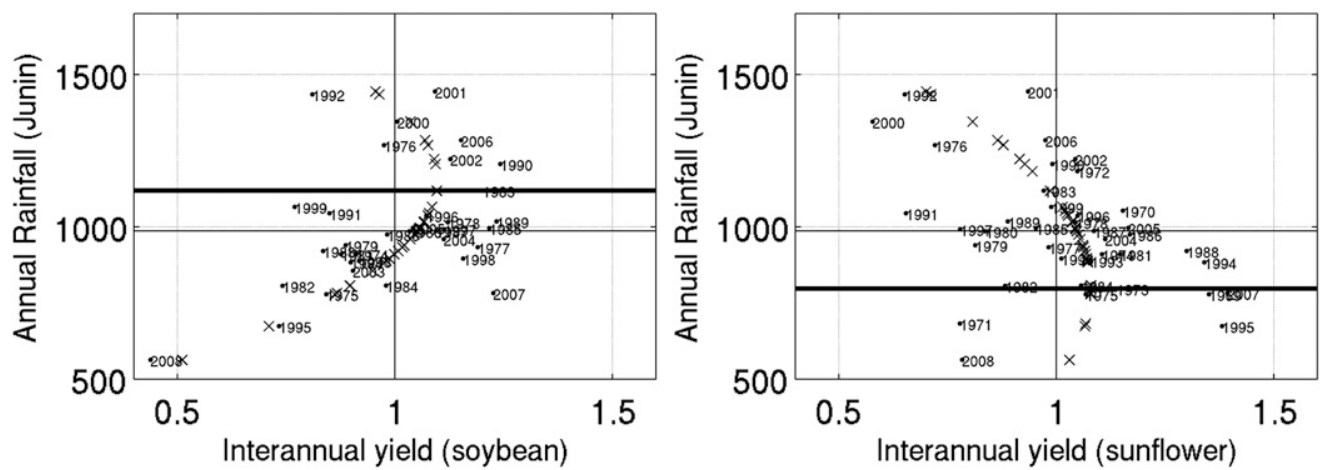

FIG. 9. Scatterplot of the interannual yield (abscissa) and annual rainfall from January to December (for wheat only) and from July to June $(+1)$ (for maize, soybean, and sunflower) in ordinates in Junín. The yield is the ratio between the raw values and the long-term trend defined as the low-pass variations $\geq 20$ years. The crosses denote the simulation of yields using a quadratic regression. The horizontal black full line is the mean annual rainfall and the thick horizontal black line is the annual rainfall maximizing the yield according to the quadratic regression. In the title of each panel, Rsq indicates the $R^{2}$ value of the quadratic regression. The F test is the significance of Rsq $\left(R^{2}\right)$ and the significance of the quadratic term $(Q$ term $)$, according to a Student's $t$ test, is also indicated.

between soybean and maize yields and annual rainfall characteristics, especially in Junín. Figures 9 and 10 show a generally large spread in yield for similar annual amounts, especially for low and mean annual rainfall (except for wheat where the spread is also large for wet years; Figs. 9a and 10a). The intra-annual distribution of rainfall across the season may be as important as, or even more than, the mean annual values. Figure 11 illustrates the subseasonal sensitivity of yield to intraannual variations in San Justo. Both years (2007/08 and 2008/09) are anomalously dry and receive almost the same amount of rainfall (697 and $661 \mathrm{~mm}$, respectively, for a long-term mean of $1028 \mathrm{~mm}$ ). The wet season lasts longer in 2007/08, including near-normal rain in SeptemberOctober, and there is no long dry spell. In 2008/09, the rainfall is more concentrated in a single 4-day wet sequence in early March, which received $24 \%$ of the annual rainfall with a daily maximum of $95 \mathrm{~mm}$. There is almost no rain in December-January at the usual peak of the summer season, or after the short wet spell in early
March (Fig. 11). The 2007/08 season leads to normal or above-normal yields, and the 2008/09 season to extremely low yields (Fig. 11).

The impact of intra-annual modulation of rainfall is explored using the rainfall anomaly across the annual cycle. A quadratic regression is fitted using amount of rainfall (RA), mean length of dry spells (DRYM), and amount of rainfall received only during wet days $>90$ th percentile (Q90) computed on sliding windows of various sizes. The most sensitive stages are summarized in Table 5. The explained variance of interannual wheat yields using RA as a predictor is only significant around March, well before the sowing period (Fig. 2 and Table 5). In San Justo, anomalously long dry spells near the end of the sowing period, and around July-September at the end of the crop cycle, appear to be detrimental (Table 5). In Junín, a weak sensitivity to Q90 is observed near the start of the sowing period around June, associating low yields with anomalously high Q90 (Table 5). For maize, the effect of RA is mostly linear with wetter-than-usual 
(a) $\mathrm{Rsq}=5 \%(\mathrm{~F}$-test $=58 \%) \mathrm{T}$ test $(\mathrm{Q}$ term $)=80 \%$

(b) $R$ sq $=10 \%(F$-test $=85 \%) T$ test $(Q$ term $)=72 \%$
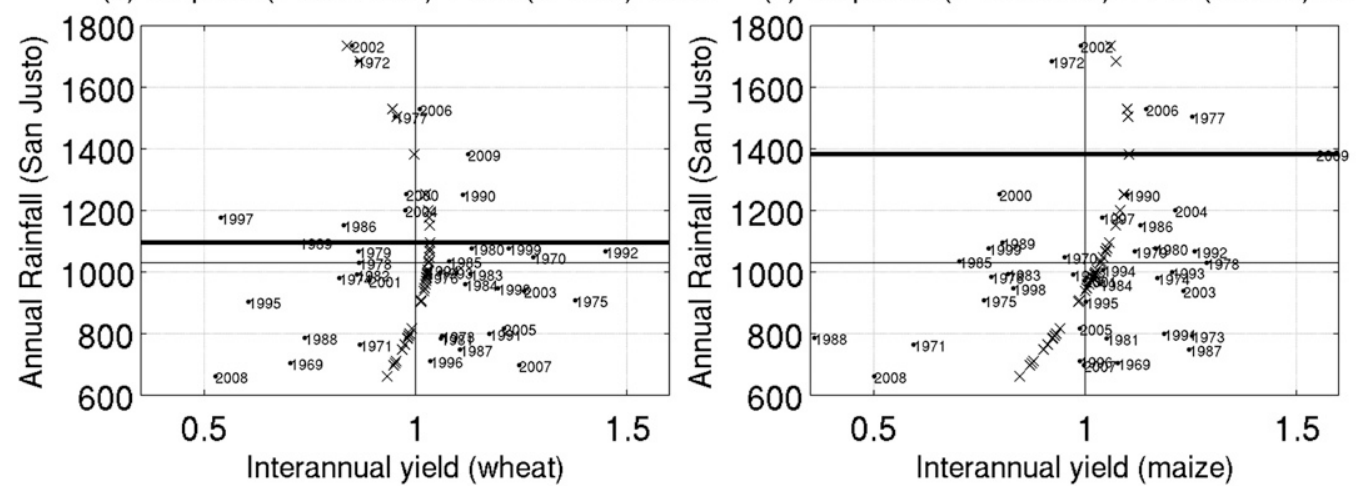

(c) Rsq $=35 \%$ (F-test $=100 \%) T$ test $(Q$ term) $=30 \%$

(d) $\mathrm{Rsq}=12 \%(\mathrm{~F}$-test $=91 \%) \mathrm{T}$ test $(\mathrm{Q}$ term $)=20 \%$
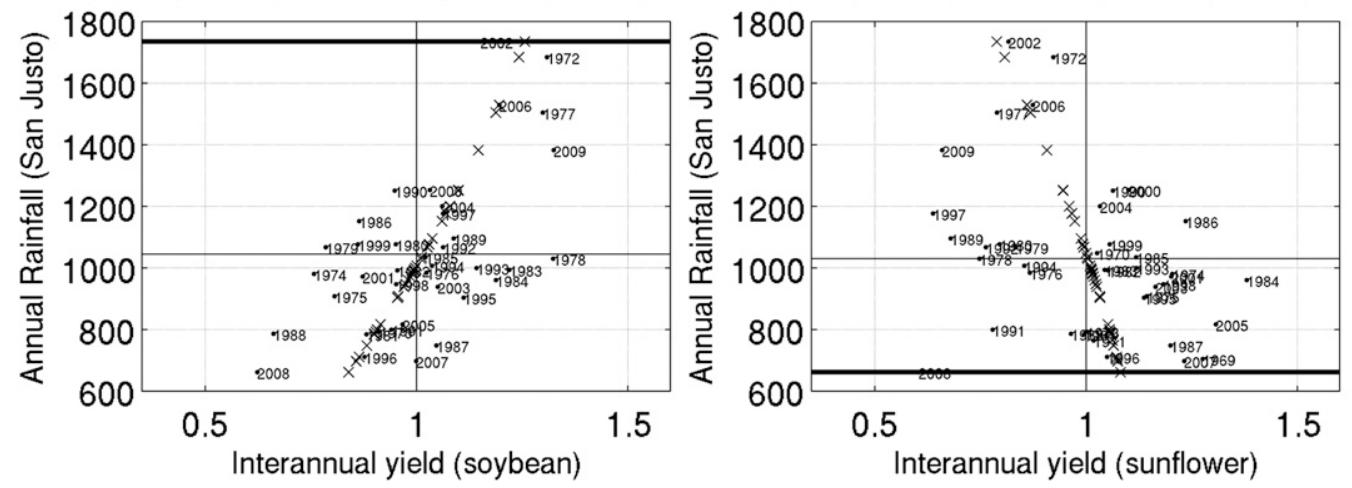

FIG. 10. As in Fig. 9, but for San Justo.

conditions associated with positive yield anomalies (Table 5). The delay between San Justo (highest sensitivity around November-December) and Junín (highest sensitivity around December-February) could partially be explained by the 1-2-month difference between sowing periods (Fig. 2). The sensitivity to DRYM is larger around sowing windows and is usually not linear due to the negative impact of long-lasting dry spells (Table 5). The sensitivity to Q90 is larger during (in San Justo) and at the end (in Junín) of the crop cycle with a positive effect of large rainfall on fitted yields. For soybeans, the sensitivity to RA lasts longer in Junín than in San Justo (Table 5). The highest fitted yields are clearly associated with positive rainfall anomalies at both sites. The sensitivity to DRYM peaks around November with a nonlinear impact of long-lasting dry spells on lowest fitted yields in Junín. The sensitivity to Q90 is delayed until February-April, close to the end of the crop cycle (Fig. 2), with a positive linear effect (Table 5). For sunflower, the relationships with RA peak around the middle of the cycle (around January) with a clear negative effect of positive rainfall anomalies, a characteristic matched by Q90 (Table 5). This is the sole case where too much rainfall is associated, on average, with lowest fitted yields.
Additional analyses are performed for soybeans, the dominant crop in terms of area and total production. Table 5 suggests that the long-term effect of RA could be divided into both a high sensitivity to the dry spell around November, as well as to the abundant wet days around February-March. Both effects are almost phaselocked in Junín and San Justo. We computed the mean length of dry spells in November and the amount of rainfall received during 90th percentile days in February-March (Figs. 12 and 13). These quantities were then used to hindcast the interannual yields using linear and quadratic models, with and without interaction between both

TABLE 4 . The $R^{2}(\times 100)$ value of the fit provided by a quadratic regression between interannual variations of yield ( $=$ ratio between the yield and the low-pass filtered yield $>20 \mathrm{yr}$ ) and the annual rainfall from 1 July to 30 June. The regression is constructed using all available years but excludes 2009 . One, two, and three asterisks denote significant value at the $90 \%, 95 \%$, and $99 \%$ level according to an $\mathrm{F}$ test.

\begin{tabular}{lcccc}
\hline \hline & Wheat & Maize & Soybean & Sunflower \\
\hline Junín & 7.5 & $33.7 * * *$ & $42.9 * * *$ & $23.3 * * *$ \\
Junín (-2008/09) & 1.6 & $20.2 * *$ & $21.1^{* *}$ & $27.7 * * *$ \\
San Justo & 4.5 & 9.7 & $35^{* * *}$ & $11.9 *$ \\
San Justo (-2008/09) & 3.3 & 4.7 & $30.7 * * *$ & $21.1 * *$ \\
\hline
\end{tabular}


(a) Daily rainfall (2007/2008) at San Justo

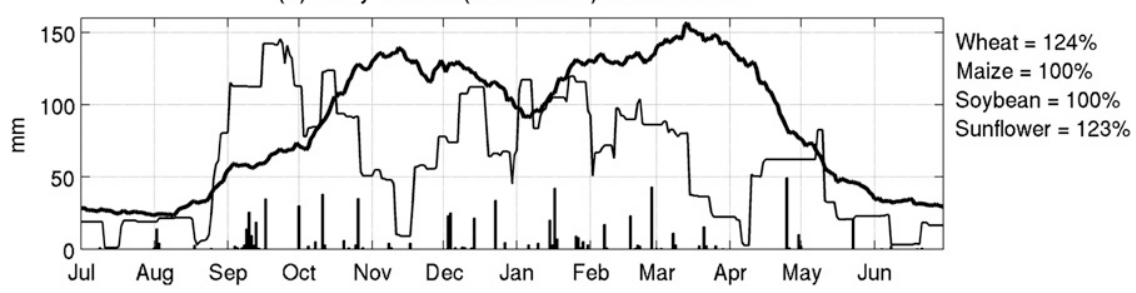

(b) Daily rainfall (2008/2009) at San Justo

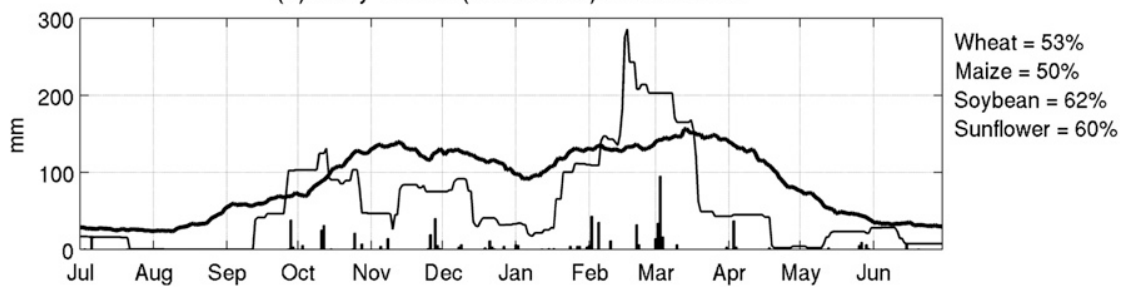

FIG. 11. Daily rainfall (as black bars) recorded in San Justo in (a) 2007/08 (annual rainfall = $697 \mathrm{~mm}$ ) and (b) 2008/09 (annual rainfall $=661 \mathrm{~mm}$ ). The black line is the sum on a running 31-day window while the black thick line is the climatology of this 31-day mean. Note that the ordinate axis differs between both panels by a factor of $\sim 2$.

predictors. The model is cross-validated with each year iteratively hindcast using parameters from the remaining years. We also considered the same models using the mean rainfall amounts in November and FebruaryMarch to evaluate the potential gain of intraseasonal characteristics compared to the usual rainfall amounts. The highest skill (evaluated here as the correlation between observed and hindcast yield) is similar at both locations (Table 6) and in both cases, positive rainfall anomalies (i.e., short dry spells in November plus abundant rainfall in February-March) favor anomalously positive yields, but both climatic characteristics are almost independent of each other. Tailored intraseasonal characteristics always explain a larger amount of variance than usual monthly/seasonal amounts of rainfall (Table 6).

\section{Discussion and conclusions}

The first topic analyzed in our paper is the perceived vulnerability to climate variability in two districts of subhumid/humid Argentinean Pampas. Both districts share the same subtropical-temperate climate, even if it is a little bit warmer in San Justo than in Junín. They also share the same recent conversion from mixed crop and livestock farming to a more specialized system dominated by transgenic soybean production (Pengue 2005, 2006). They differ in subtle ways: for example, ENSO events have a stronger impact on San Justo than Junín (Messina et al. 1999) and this slight difference is well perceived by farmers (Fig. 5). The main structural difference, however, is perhaps not related to the basic climatic state and variations, but rather to soils. Junín has more mineral-rich soil, and therefore has slightly higher mean yields, than San Justo (Fig. 4).

From a systemic point of view, San Justo's configurationthat is, similar climate risks and production costs as Junín, but lower mean yields $\left(2-2.5 \mathrm{tha}^{-1}\right.$ vs $3.5-4 \mathrm{tha}^{-1}$ for soybean)-reflects a larger agricultural sensitivity to economic factors such as international commodities market prices, which are highly variable, and commercialization rules of the national market. The investment returns essentially depend on commodities prices at Chicago's Board of Trade as well as on national fiscal policies. In this sense, San Justo's farmers rank the influence of external markets and Argentinean government agricultural policies as the major risk variables, while Junín's farmers clearly cite climate factors.

Farmers primarily emphasized the role of drought, and then of flood, as the major adverse climatic factors (Figs. 5 and 6), well before any thermal event (such as frost or extreme temperatures, including heat waves). In fact, the observed relationship between yields and temperature is weak in San Justo and only slightly higher in Junín (Fig. 8). The perception of both floods and drought as adverse effects could be ideally fitted within a quadratic function where low yields could be related either to anomalously positive or negative rainfall, while the highest yields would be related to nearnormal rainfall. Using only annual rainfall values (Figs. 9 and 10) this relationship somewhat corroborates the farmers' perception in Junín, where the main climaterelated threat is tied to low rainfall amounts, with some saturation associated with high rainfall amounts (Podestá 
TABLE 5. Sensitive stages of the crop cycle. Three climatic variables are tested independently: amount of rainfall, mean dry spell length, and amount of rainfall in days receiving a daily rainfall above the $90 \%$ percentile (P90) estimated from the whole year. Also, $R^{2}$ (4th column) is the explained variance of interannual variability of yields by the climatic variables (in \%). The $p$ value of $R^{2}$ (5th column) is the probability that $R^{2}$ is zero. The $p$ value of the quadratic term (6th column) is the probability that the quadratic term is zero. The last two columns give the standardized anomaly corresponding to the highest ( 7 th column) and lowest (8th column) yields simulated by the quadratic regression. For each crop and district, the bold line emphasizes the largest $R^{2}$.

\begin{tabular}{|c|c|c|c|c|c|c|c|}
\hline $\begin{array}{c}\text { Climatic } \\
\text { variables }\end{array}$ & $\begin{array}{c}\text { Crop and } \\
\text { district }\end{array}$ & Time period & $\begin{array}{c}R^{2} \\
(\%)\end{array}$ & $\begin{array}{c}p \\
\text { value } \\
\text { of } R^{2}\end{array}$ & $\begin{array}{c}p \text { value of } \\
\text { quadratic } \\
\text { term }\end{array}$ & $\begin{array}{l}\text { Standardized } \\
\text { anomaly } \\
\text { corresponding } \\
\text { to highest yield }\end{array}$ & $\begin{array}{l}\text { Standardized } \\
\text { anomaly } \\
\text { corresponding } \\
\text { to lowest yield }\end{array}$ \\
\hline Amount & Wheat Junín & Early March-early April & 16 & 0.04 & 0.66 & -1.67 & 3.49 \\
\hline Amount $>$ P90 & Wheat Junín & Early February-early April & 25 & $<\mathbf{0 . 0 1}$ & 0.04 & -1.41 & 1.09 \\
\hline Amount $>$ P90 & Wheat Junín & Late May-late June & 15 & 0.04 & 0.32 & -0.27 & 1.96 \\
\hline Amount & Wheat S. Justo & Mid February-early April & 14 & 0.05 & 0.22 & 2.13 & -1.41 \\
\hline Dry spell length & Wheat S. Justo & Late March-early May & 25 & $<\mathbf{0 . 0 1}$ & 0.31 & -1.04 & 2.39 \\
\hline Dry spell length & Wheat S. Justo & Mid July-late September & 13 & 0.07 & 0.33 & 0.27 & 5.76 \\
\hline Amount & Maize Junín & Late November-early March & 26 & $<0.01$ & 0.81 & 2.61 & -1.50 \\
\hline Dry spell length & Maize Junín & Mid October-late November & 30 & $<0.01$ & 0.05 & -0.53 & 3.93 \\
\hline Dry spell length & Maize Junín & Late December-mid January & 32 & $<\mathbf{0 . 0 1}$ & 0.89 & -0.93 & 4.32 \\
\hline Amount $>$ P90 & Maize Junín & Late January-early March & 16 & 0.04 & 0.18 & 2.14 & -1.01 \\
\hline Amount & Maize S. Justo & Late October-late December & 20 & 0.02 & 0.62 & 2.25 & -1.36 \\
\hline Dry spell length & Maize S. Justo & Late October-early December & 23 & $<\mathbf{0 . 0 1}$ & 0.02 & -1.41 & 1.99 \\
\hline Amount $>$ P90 & Maize S. Justo & Late October-late January & 19 & 0.02 & 0.12 & 1.62 & -1.13 \\
\hline Amount & Soybean Junín & Mid October-early February & 52 & $<\mathbf{0 . 0 1}$ & $<\mathbf{0 . 0 1}$ & 1.19 & $-\mathbf{1 . 8 5}$ \\
\hline Dry spell length & Soybean Junín & Late October-late November & 36 & $<0.01$ & 0.10 & -0.71 & 4.33 \\
\hline Amount $>$ P90 & Soybean Junín & Late January-mid March & 17 & 0.05 & 0.73 & 3.14 & -1.31 \\
\hline Amount & Soybean S. Justo & Late December-mid March & 21 & 0.01 & 0.35 & 3.27 & -1.07 \\
\hline Dry spell length & Soybean S. Justo & Early November-late November & 21 & 0.02 & 0.90 & -1.13 & 3.42 \\
\hline Amount $>$ P90 & Soybean S. Justo & Mid January-early April & 33 & $<\mathbf{0 . 0 1}$ & $\mathbf{0 . 3 3}$ & 3.93 & $-\mathbf{1 . 0 2}$ \\
\hline Amount & Sunf. Junín & Mid December-mid January & 15 & 0.05 & 0.87 & -1.22 & 3.13 \\
\hline Dry spell length & Sunf. Junín & Mid July-mid September & 20 & 0.02 & 0.97 & 3.32 & -0.73 \\
\hline Amount $>$ P90 & Sunf. Junín & Late October-early January & 21 & 0.01 & 0.25 & -1.18 & 1.42 \\
\hline Amount & Sunf. S. Justo & Early December-late February & 27 & $<\mathbf{0 . 0 1}$ & 0.43 & -1.37 & $\mathbf{2 . 5 2}$ \\
\hline Dry spell length & Sunf. S. Justo & Early February-late Febraury & 25 & $<0.01$ & 0.14 & 0.96 & -1.62 \\
\hline Amount $>$ P90 & Sunf. S. Justo & Early January-early March & 23 & $<0.01$ & 0.05 & 0.84 & 2.20 \\
\hline
\end{tabular}

et al. 1999; Magrin et al. 2005). The adverse effect of large rainfall amounts is not as evident in San Justo (Fig. 10). Sunflower yield data reveal the stronger adverse effect of high rainfall amounts in Junín, while wheat seems to be the least sensitive to rainfall variability.

By definition, any annual value smooths out any intraannual modulation involving reversed polarities across the crop cycle: a gain associated with a positive anomaly at one stage could be canceled out by a loss at another stage. Such inversions seem not to happen for the four crops studied here, at least not for the analyzed rainfall characteristics. Moreover, the impact seems restricted to specific stages of the crop cycle, but seems rather homogeneous when the explained variance is significant (Table 5). We have shown that nonlinearity is largely induced by the negative effect of long-lasting dry spells during the first half of the crop cycle, while the effect of Q90 (and rainfall amounts) is usually linear and stronger from the middle to the end of the crop cycle.
On average, Q90 and rainfall amounts have a positive effect on yields except for sunflower (and wheat in Junín). Deconstruction of the seasonal RA into intraseasonal components (such as mean length of dry spell or Q90) agrees with previous studies that use only seasonal (or monthly) amounts as the predictor of yields (Podestá et al. 1999; Magrin et al. 2005; d'Orgeval et al. 2010). Additionally, the ranking of flood as the second greatest adverse climatic factor by the farmers does not match with the observed impact (i.e., positive except for sunflower) of heavy rainfall on yields. In contrast, heavy rainfall does not appear as an adverse factor (i.e., associated on average with negative yields anomalies) at intra-annual time scales, except for sunflower, running contrary to the yields following large rainfall amounts observed for soybeans and maize in Junín (Fig. 9), as well as with farmers' perceptions (Fig. 5). This partial discrepancy could be explained if the negative impact of large rainfall is diluted across the crop cycle. In that case, it will appear at the annual time scale but not 
(a) Mean length of dry spell in November

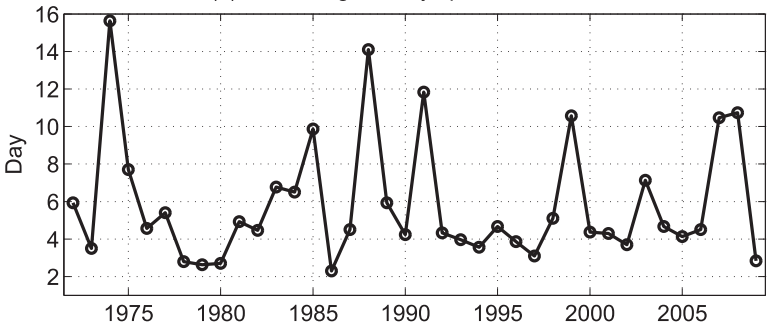

(b) Amount of rainfall in $\mathrm{P} 90$ days in Feb-March

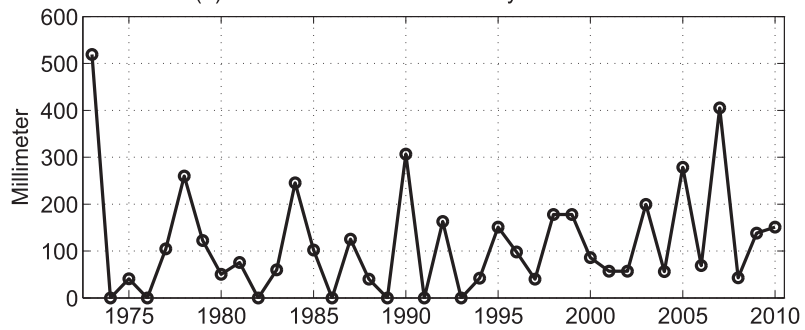

(c) Observed and hindcast Yields

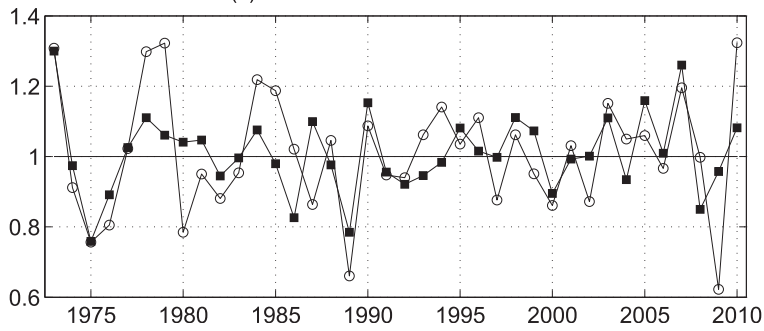

FIG. 12. (a) Mean length of dry spell (in days) in November; (b) rainfall received during wet days above the $90 \%$ percentile of wet day in February-March in (in mm); (c) hindcast (line + black square) vs observed (line + circle) interannual yields of soybean in San Justo. The hindcast is given by a quadratic regression without interaction using the two rainfall quantities as predictors of interannual anomalies of soybean yield in cross-validation.

necessarily at the intra-annual scale, due to the absence of phase-locking.

We examined the 10 years with the largest residuals from the quadratic regression, involving the mean length of dry spells in November and rainfall amount during 90th percentile days in February-March, as predictors of the interannual variations of soybean in Junín where the nonlinearity between annual rainfall and yields is the strongest (Fig. 8). These 10 years show a relative positive effect of short dry spells in November and/or large rainfall amounts in February-March, somewhat counteracted by any other adverse factor (not necessarily a climatic one). In these years, heavy rainfall (i.e., many 90th percentile days clustered in 1-2 months) sometimes occurs, but not at the same time (around September in 1982/83, around April-May in 1992/93, from mid-March to late May in 1992/93, in October-November and January in $2000 / 01$, etc.). So, while the beneficial effect of (a) Mean length of dry spell in November

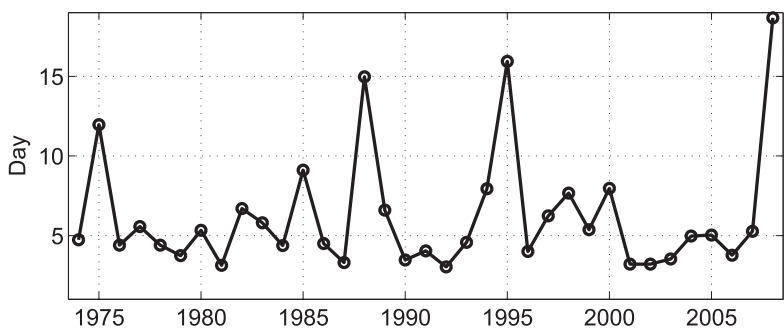

(b) Amount of rainfall in P90 days in Feb-March

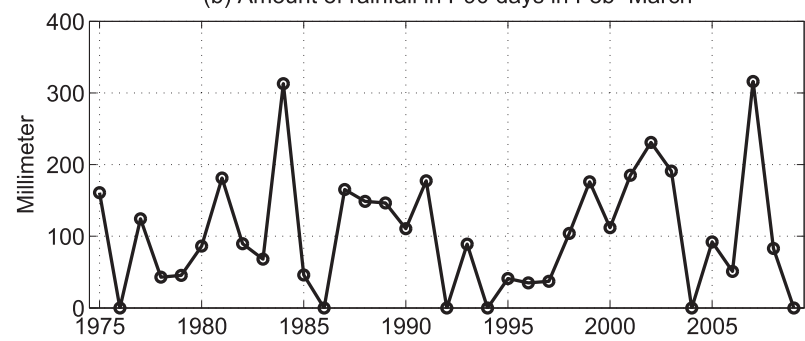

(c) Observed and hindcast Yields

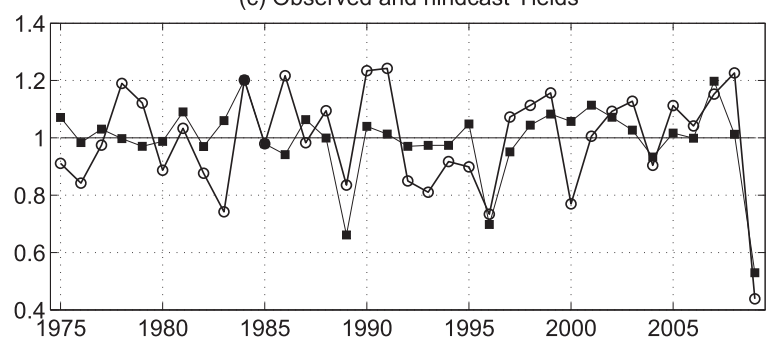

FIG. 13. As in Fig. 12, but for Junín. The hindcast is given as a linear regression without interaction using the two rainfall quantities as predictors of interannual anomalies of soybean yield in cross-validation.

short dry spells and large rainfall amounts (especially for soybeans and maize) is captured on average, the adverse effect of too much rainfall seems less systematic and less phase-locked with the crop cycle. In other words, the farmers' perception is not necessarily distorted and could even capture linear and nonlinear effects phaselocked with the crop cycle, as well as scattered effects. We have also shown that analysis of tailored intraseasonal characteristics (such as mean length of dry spells or rainfall amounts received during 90th percentile days) accounts for more variance than rainfall amounts alone (Figs. 12 and 13).

The above climate-yield relationships are complicated in the case of soybeans, due to the fact that crop statistics do not differentiate between the two harvests. The percentage of both harvests is variable among the years, since a relatively bad first harvest may promote an intense sowing for the second half of the season. If this season succeeds, the annual production will be dominated by the second harvest. The average yield would fall between a deficit and a surplus. Unfortunately, there is no 
TABLE 6. Correlation $(\times 100)$ between observed and hindcast yields of soybean in Junín and San Justo. The highest correlation for each set of predictor and location is emphasized in bold. The hindcast is made through cross-validated regression using mean length of dry spell (DRYM) in November and rainfall received during wet days in the $90 \%$ percentile (Q90) in February-March or rainfall amounts in November and February-March (RA). Four different regressions are tested: linear without interaction, linear with interaction, quadratic without interaction, and quadratic with interaction.

\begin{tabular}{lcccr}
\hline \hline & Linear - interaction & Linear + interaction & Quadratic - interaction & Quadratic + interaction \\
\hline Junín DRYM + Q90 & 47 & 39 & 63 & 61 \\
Junín RA & 41 & 37 & 29 & -31 \\
San Justo DRYM + Q90 & 60 & 56 & 56 & 50 \\
San Justo RA & 42 & 38 & 40 & 36 \\
\hline
\end{tabular}

objective measure to systematically weigh the annual yield by two coefficients. The climate diagnostic seems to indicate that the most sensitive stages of soybean production in Junín and San Justo are mostly tailored to the first harvest between winter/spring and the next autumn (Table 2).

As shown in section 3 , climate factors cannot be isolated from the technological, socioeconomic, and agronomic conditions of the whole productive system. Usually, most of the scientific literature on farmers' adaptation to climate variability focuses on the analysis of geographical and cropping diversification strategies. In this paper, we stress the need to consider different socioproductive farmer profiles to identify specific strategies for coping with climate vulnerability. This social significance of climate events evidences the need to integrate socioproductive practices in climate and yield impact analyses, as well as in the design of climate change adaptation public policies. In fact, for an agribusiness farmer able to geographically diversify his production, carry out logistical strategies, modify territories to mitigate some adverse climate events (e.g., channeling in case of floods), or to negotiate the prices of labor and other inputs, it is clear that a regional-scale climatic diagnosis (including seasonal prediction) is useful since this kind of stakeholder conducts business at this spatial scale. In contrast, for a capitalized and a noncapitalized farmer, whose productive (and life) scale is located at the district level, a climatic diagnosis is useful only if it refers to a more local scale.

The observed strategies facing floods and droughts are different: agribusiness and capitalized farmers are able to integrate economic, social, and cognitive resources to plan successful strategies that allow them to mitigate adverse climate events. On the contrary, noncapitalized farmers are not only strongly affected by the impacts of both hazards, but also by some of the mitigating strategies implemented by their agribusiness and capitalized neighbors. For example, their fields could be flooded from private channel drainage, they may suffer from a lack of available agricultural services monopolized by the agribusiness profile, and consequently may not have full control over their crop calendar, etc. Therefore, we have shown the importance of analyzing climate events as a multidimensional phenomenon (Meze-Hausken 2007), whose social significance is informed by participants according to their position in the socioproductive and economic structure. The content and form in which scientific knowledge of climate events is presented should speak to the needs of each farmer profile.

We have observed that soybean and maize yields are the most sensitive to rainfall anomalies. This is especially relevant because of the recent transition of the Argentinean Pampas from a mixed crop system (cereal, oil seed, livestock, etc.) to a more specialized agriculture system dominated by a single transgenic soybean crop. As a result, the agriculture sector has become more vulnerable to rainfall variability, and producers may have developed a higher sensitivity to climate variation. This sensitivity has turned into a crucial cognitive tool allowing the producers to consider and plan their activity in an integrated way, identifying possible successful strategies for coping with adverse climate events. Analysis of climate's social significance points to a complex relationship between producers, their perceptions of climate, and the strategies implemented to combat adverse climatic factors. Moreover, perceptions of the relationship between crop variation and climate must be considered in terms of both data format (statistical, narrative, graphical, etc.) and spatiotemporal scales. The climate and society relationship is not linear and requires an interaction between interdisciplinary researchers and stakeholders (Funtowicz and Ravetz 1993; Gallopin et al. 2001).

Acknowledgments. This work has been partly funded by an Agence Nationale de la Recherche Grant VULN008-01 PICREVAT. This research has been also funded by EU-FP7 Grant CLARIS (coordinator: Jean-Philippe Boulanger) and we thank also Caroline Phan (SupAGRO, Dijon, France), who participated in the surveys. We thank Junín and San Justo farmers for their collaboration during this research, as well as INTA Rafaela 
and National Meteorological Service. We thank Mea Halperin (International Research Institute for Climate and Society, Columbia University) for her careful reading of the revised version of this paper.

\section{APPENDIX}

\section{Quadratic Function}

Most of the statistical analyses are based on regression with interannual variation of yield as predictand $(=Y)$ and climatic variables (annual and 61-day running average, or sum, of rainfall amount, mean length of dry spell, temperature anomalies etc.) as predictors $(=X)$. Note that $X$ and $Y$ are expressed as anomalies relatively to their respective long-term means. In case of yields, the mean is the varying low-pass filtered (cutoff $=20 \mathrm{yr}$ ) variation to take into account the general increase all along the period. The farmers' perceptions, scaling drought and flood as major adverse climatic events (see section 3 ), could be ideally represented by a second-order polynomial function including a quadratic term. The quadratic function without interaction using a single predictor has the following form:

$$
Y^{\prime}=a_{1} X+a_{2} X^{2}+b,
$$

where $a_{1}$ is the linear term, $a_{2}$ is the quadratic term, and $b$ is the constant term. Additional terms could be included to describe the linear and quadratic interaction(s) between multiple predictors. The overall quality of the model is evaluated with the "explained" variance of the predictand by the predictor(s) (i.e., the squared linear correlation, $R^{2}$, between $Y$ and $Y^{\prime}$ ). This is tested against the null hypothesis that the variations of $X$ does not explain those of $Y$ using an $\mathrm{F}$ test. The significance of quadratic and linear terms against the null hypothesis that they equal zero is tested using a Student's $t$ test. If $a_{1}$ is zero and $a_{2}$ significantly different from zero, the regression could be illustrated graphically by a parabola whose axis of symmetry is parallel to the axis of the predictand. If $a_{2}$ is significantly negative, yields are maximized for near-normal climatic conditions while the largest negative and positive climatic anomalies are associated with the worst yields. The case with $a_{2}$ significantly positive (i.e., lowest yields associated to near-normal climate anomalies) never happens in this study. If $a_{2}$ is zero and $a_{1}$ significantly different from zero, it means a linear relationship between yields and climatic conditions, which is represented graphically by a straight line. Any mixed graphical shape between a parabola and a straight line would be associated with both $a_{1}$ and $a_{2}$ significantly different from zero.

\section{REFERENCES}

Aberra, Y., 2012: Perceptions of climate change among members of the House of Peoples' Representatives, Ethiopia. J. Risk Res., 15, 771-785, doi:10.1080/13669877.2012.657219.

Agar, M., 2004: We have met the other and we're all nonlinear: Ethnography as a nonlinear dynamic system. Complexity, 10, 16-24, doi:10.1002/cplx.20054.

Althabe, G., 1990: Ethnologie du contemporain et enquête de terrain. Terrain, 14, 126-131, doi:10.4000/terrain.2976.

Alvarez, R., and R. S. Lavado, 1998: Climate, organic matter and clay content relationships in the Pampa and Chaco soils. Geoderma, 83, 127-141, doi:10.1016/S0016-7061(97)00141-9.

Bonatti, M., 2011: Cambios climáticos, percepciones humanas y desarrollo rural. M.A. thesis, Universidad de Buenos Aires, FAUBA, 114 pp.

Boulanger, J. P., 2012: Development, adaptation and mitigation to climate risks. ECOCLIMASOL-IRD, UMI_100424, 64 pp. [Available online at http://www.cima.fcen.uba.ar/UMI/ documents/2011/UMI_110424_Boulanger.pdf.]

Byun, H. R., and D. A. Wilhite, 1999: Objective quantification of drought severity and duration. J. Climate, 12, 2747-2756, doi:10.1175/1520-0442(1999)012<2747:OQODSA > 2.0.CO;2.

Caviglia, O. P., and F. H. Andrade, 2010: Sustainable intensification of agriculture in the Argentinean Pampas: Capture and use efficiency of environmental resources. Amer. J. Plant Sci. Biotechnol., 3, 1-8.

CNPyV, 2010: Censo Nacional de Población yViviendas. Instituto Nacional de Estadíasticas y Censos (INDEC). [Available online at http://www.censo2010.indec.gov.ar/resultadosdefinitivos.asp.]

Diaz-Zorita, M., G. A. Duarte, and J. H. Grove, 2002: A review of no-till systems and soil management for sustainable crop production in the subhumid and semiarid Pampas of Argentina. Soil Tillage Res., 65, 1-18, doi:10.1016/S0167-1987(01)00274-4.

d'Orgeval, T., J. P. Boulanger, M. J. Capalbo, E. Guevara, O. Penalba, and S. Meira, 2010: Yield estimation and sowing date optimization based on seasonal climate information in the three CLARIS sites. Climatic Change, 98, 565-580, doi:10.1007/ s10584-009-9746-4.

Ebisuzaki, W., 1997: A method to estimate the statistical significance of a correlation where the data are serially correlated. J. Climate, 10, 2147-2153, doi:10.1175/1520-0442(1997) $010<2147$ :AMTETS $>2.0$. CO;2.

Funtowicz, S., and J. R. Ravetz, 1993: Science for the post-normal age. Futures, 25, 739-755, doi:10.1016/0016-3287(93)90022-L.

Gallopin, G., S. Funtowicz, M. O'Connor, and J. R. Ravetz, 2001: Science for the 21st century: From social contract to the scientific core. Int. J. Soc. Sci., 168, 219-229, doi:10.1111/ 1468-2451.00311.

Garcia, F. O., M. Ambroggio, and V. Truco, 2000: No-tillage in the Pampas of Argentina: A success story. Better Crops Int., 14, 24-27.

Gibbons, M., 1999: Science's new social contract with society. Nature, 402, C81-C84, doi:10.1038/35011576.

Gieryn, T., 1999: Cultural Boundaries of Science: Credibility on the Line. University of Chicago Press, 398 pp.

Hernández, V., 2007: Entrepreneurs 'sans terre' et 'pasteurs de la connaissance': Une nouvelle bourgeoisie rurale? Turbulences monétaires et sociales: L'Amérique latine dans une perspective comparée, V. A. Hernández et al., Eds., L'Harmattan, 209-258. 
_ peanas: Usos del territorio. El Agro como Negocio: Producción, Sociedad y Territorios en la Globalización, C. Gras and V. Hernández, Eds., Biblos, 123-150.

_, E. Muzi, and F. Fossa Riglos, 2013b: Figuras socioproductivas de la ruralidad globalizada. El Agro como Negocio: Producción, Sociedad y Territorios en la Globalización, C. Gras and V. Hernández, Eds., Biblos, 151-170.

Janicot, S., V. Moron, and B. Fontaine, 1996: Sahel droughts and ENSO dynamics. Geophys. Res. Lett., 23, 515-518, doi:10.1029/ 96GL00246.

Keyantash, J., and J. A. Dracup, 2002: The quantification of drought: An evaluation of drought indices. Bull. Amer. Meteor. Soc., 83, 1167-1180.

Leiserowitz, A. A., 2005: American risk perceptions: Is climate change dangerous? Risk Anal., 25, 1433-1442, doi:10.1111/ j.1540-6261.2005.00690.x.

_ 2007: International public opinion, perception, and understanding of global climate change. Fighting climate change: Human solidarity in a divided world, Human Development Rep. 2007/2008 Occasional Paper, Yale University, $39 \mathrm{pp}$.

Letson, D., I. Llovet, G. Podestá, F. Royce, V. Brescia, D. Lema, and G. Parellada, 2001: User perspectives of climate forecasts: Crop producers in Pergamino, Argentina. Climate Res., 19, 57-67, doi:10.3354/cr019057.

Magrin, G. O., M. I. Travasso, and G. R. Rodriguez, 2005: Changes in climate and crop production during the 20th century in Argentina. Climatic Change, 72, 229-249, doi:10.1007/ s10584-005-5374-9.

Mertz, O., C. Mbow, A. Reenberg, and A. Diouf, 2009: Farmers' perceptions of climate change and agricultural adaptation strategies in rural Sahel. Environ. Manage., 43, 804-816, doi:10.1007/s00267-008-9197-0.

Messina, C. D., J. W. Hansen, and A. J. Hall, 1999: Land allocation conditioned on ENSO phases in the Pampas of Argentina. Agric. Syst., 60, 197-212, doi:10.1016/S0308-521X(99)00032-3.

Meze-Hausken, E., 2004: Contrasting climate variability and meteorological drought with perceived drought and climate change in northern Ethiopia. Climate Res., 27,19-31, doi:10.3354/ cr027019.

— 2007: Seasons in the sun-Weather and climate front-page news stories in Europe's rainiest city, Bergen, Norway. Int. J. Biometeor., 52, 17-31, doi:10.1007/s00484-006-0064-5.

, 2008: On the (im-)possibilities of defining human climate thresholds. Climatic Change, 89, 299-324, doi:10.1007/ s10584-007-9392-7.
Pengue, W. A., 2005: Transgenic crops in Argentina: The ecological and social debt. Bull. Sci. Technol. Soc., 25, 314-322, doi: $10.1177 / 0270467605277290$.

_ 2006: Transgenic crops in Argentina and its hidden costs. Proc. IV Biennial International Workshop "Advances in Energy Studies”, Campinas, Sao Paulo, Brazil, State University of Campinas, 91-101.

Podestá, G. P., C. D. Messina, M. O. Grondona, and G. O. Magrin, 1999: Associations between grain crop yields in centraleastern Argentina and El Niño-Southern Oscillation. J. Appl. Meteor., 38, 1488-1498, doi:10.1175/1520-0450(1999)038<1488: ABGCYI>2.0.CO;2.

_ , and Coauthors, 2002: Use of ENSO-related climate information in agricultural decision making in Argentina: A pilot experience. Agric. Syst., 74, 371-392, doi:10.1016/ S0308-521X(02)00046-X.

, and Coauthors, 2009: Decadal climate variability in the Argentine Pampas: Regional impacts of plausible scenarios on agricultural systems. Climate Res., 40, 199-210, doi:10.3354/ cr00807.

Sanchez-Cortés, M. S., and E. Lazos Chavero, 2011: Indigenous perception of changes in climate variability and its relationship with agriculture in a Zoque community of Chiapas, Mexico. Climatic Change, 107, 363-389, doi:10.1007/s10584-010-9972-9.

Schlindwein, S., S. Siebe, and V. A. Hernandez, 2011: Land use change, agriculture and socio-economic implications: CLARIS LPB WP8. CLIVAR Exchanges, No. 57, International CLIVAR Project Office, Southampton, United Kingdom, 8-31.

Slegers, M. F. W., 2008: "If only it would rain": Farmers' perceptions of rainfall and drought in semi-arid central Tanzania. J. Arid Environ., 72, 2106-2123, doi:10.1016/j.jaridenv.2008.06.011.

Speranza, C. I., B. Kiteme, and U. Wiesmann, 2008: Droughts and famines: The underlying factors and the causal links among agro-pastoral households in semi-arid Makueni district, Kenya. Global Environ. Change, 18, 220-233, doi:10.1016/ j.gloenvcha.2007.05.001.

Thomas, D., C. Twyman, H. Osbahr, and B. Hewitson, 2007: Adapation to climate change and variability: Farmer responses to intra-seasonal precipitation trends in South Africa. Climatic Change, 83, 301-322, doi:10.1007/s10584-006-9205-4.

Tschakert, P., 2007: Views from the vulnerable: Understanding climatic and other stressors in the Sahel. Global Environ. Change, 17, 381-396, doi:10.1016/j.gloenvcha.2006.11.008.

Viglizzo, E. F., Z. E. Roberto, F. Lértora, E. Lopez Gay, and J. Bernardos, 1997: Climate and land-use change in field-crop ecosystems of Argentina. Agric. Ecosyst. Environ., 66, 61-70, doi:10.1016/S0167-8809(97)00079-0. 